\title{
Household Unemployment and the Labour Supply of Married Women
}

\author{
Paul Bingley and lan Walker
}

Working Paper 97-03

January 1997 


\author{
Published by \\ Centre for Labour Market and Social Research \\ Science Park Aarhus \\ Gustav Wieds Vej 10C, 8000 Aarhus C, Denmark
}

Editor: Henning Bunzel

Copyrights: Paul Bingley and lan Walker

ISSN 0908-8962 


\title{
Household Unemployment and the Labour Supply of Married Women
}

\author{
Paul Bingley and lan Walker
}

\author{
Working Paper 97-03 \\ January 1997
}

JEL classifications: C31, C35, D12, J22

Keywords: Labour supply, unemployment, added \& discouraged workers

\begin{abstract}
A recent reform to the UK Unemployment Insurance (UI) system has reduced the duration of entitlement from 12 to 6 months. The UI and welfare systems interact in the UK in such a way that exhaustion of UI for married individuals has potentially large disincentive effects on the labour supply of spouses.

A model of labour supply is estimated for married women allowing for endogenous unemployment durations of husbands and wives, using 43531 married couples drawn from UK Family Expenditure Surveys 1978-92. Evaluating the impact of the reform requires that we distinguish between transfer programme induced incentive effects and any correlation between labour supply and wages within couples; complementarity between the leisure times of spouses; and a discouraged worker effect.
\end{abstract}

We find that shifting households with a medium duration unemployed husband from UI onto Income Support, the main UK welfare programme, increases the wife's probability of nonparticipation by $3.5 \%$, mainly at the expense of part-time work. Should the husband find employment, the wife's probabilities of part-time and full-time work will increase by 2.3 and $9.0 \%$ respectively, about half of which is due to the welfare system. Thus the net effect depends on the extent to which the reform affects employment of married men directly. It seems unlikely that the effect would be sufficiently strong that the net effect on married women would be beneficial.

\section{Acknowledgement}

Financial support from the Danish National Research Foundation for the CLS at the University of Aarhus and the Aarhus School of Business, and the UK Economic and Social Research Council for the Centre for the Microeconomic Analysis of Fiscal Policy at the Institute for Fiscal Studies are gratefully acknowledged. The work is part of a programme of research into welfare and labour market participation funded by the Leverhulme Trust under research grant F/368/F. The data has been made available to us with the permission of the Controller of Her Majesty's Stationary Office by the ESCR Data Archive. The usual disclaimer applies.

\section{Address}

Ian Walker, Keele University, Keele, Staffordshire ST5 5BG, UK, Institute for Fiscal Studies, 7 Ridgmount St., London WC2A 2AE, UK

Paul Bingley, CLS, Science Park, Gustav Wieds Vej 10, DK-8000 Aarhus C, Denmark, e-mail:pbingley@cls.dk. 



\section{Introduction}

The adverse work incentive effects of Unemployment Insurance (UI) and Unemployment Assistance (UA) programmes (such as Income Support (IS) in the UK and Aid for Families with Dependent Children (AFDC) in the USA) are well known. UK and US welfare policy has emphasised reducing out-of-work transfer programme caseload through promoting supply-side policies to expand employment. For example, the expansion of in-work transfer programmes (Family Credit (FC) in the UK and Earned Income Tax Credit (EITC) in the US) have been important elements of recent reforms. The reduction in programme participants per se has been pursued by reducing real net entitlements, tightening eligibility restrictions and time-limitations ${ }^{1}$. Indeed, several states in the US have used their waivers to impose time limits on AFDC (see Hoynes, 1996c). In the UK UI entitlement duration has recently been reduced from 12 to 6 months, the shortest among OECD countries (together with the US and Italy (see OECD, 1996a)). UI in the UK has been renamed the Job Seeker's Allowance.

This UK reform continues the move away from insurance-related benefits ${ }^{2}$ towards reliance on income-tested assistance for the unemployed (Atkinson and Micklewright, 1989) since once UI entitlement is exhausted unemployed individuals may be entitled, subject to a family means test, to claim Income Support. Thus, the reform is also a shift away from transfers made on an individual basis (with the exception of a wife's earnings allowance in the UI system) to transfers based on family income which has implications for the labour supply decisions of all family members.

This paper addresses the general question of what the effect of time limited welfare might be, as well as the specific policy issue for the UK. Indeed, the policy was introduced in the UK to promote the incentive to shorten the duration of unemployment and the potential impact that the change would have on the incentives for wives of unemployed men to work has not been considered.

The estimation of family labour supply models has been developed in Ashenfelter and Heckman (1974), Heckman and MaCurdy (1980), Hausman and Ruud (1984) and Blundell and Walker (1986). A reduction in family income due to the unemployment of the husband will lead to an increase in the probability that the wife enters the labour force and an increase in wife's

1 For surveys of the recent welfare reforms see Atkinson (1995) on the UK and Hoynes (1996c) on the US.

2 UK transfer programmes are said to be insurance-related if entitlement to them is generated by virtue of being in a particular labour market position (eg unemployed) and having paid social security contributions (called National Insurance contributions in the UK) for the requisite period of time prior to the spell of unemployment. 
hours conditional on participation, if leisure is a normal good and leisures are separable in the utility function ${ }^{3}$. This phenomemon has sometimes been termed the Added Worker Effect (AWE).

Heckman and MaCurdy (1980) show that the AWE should be small in a life-cycle context with intertemporal separability and perfect credit markets. The argument is that the income reduction from a temporary spell of husband's unemployment is small relative to lifetime income. The wives of men who face a higher unemployment risk should have permanently higher hours and earnings, not just when the husband is actually unemployed. That is, if the unemployment shock is transitory, it should not distort the inter-temporal allocation of wife's labour.

Thus, in practice, the magnitude of the AWE depends on, among other factors, the relative ease with which households can adjust to income loss in other ways besides changes in wife's hours: for example, through more intensive husband job search or through borrowing. Liquidity constraints mean that families may have inadequate access to resources for consumption smoothing, so wife's hours may well need to increase during the spell of husband's unemployment. Dynarski and Sheffrin (1987) show that even in a life-cycle model with perfect capital markets, consumption may respond to job loss if it conveys information about lifetime prospects. So a life-cycle response to perceived greater unemployment risk may be an increase in labour supply during the spell of unemployment. However, the extent to which spousal labour supply adjustments can maintain family income when another household member is unemployed is limited by married women's relatively low earnings potential ${ }^{4}$.

UI and UA transfer programmes provide a state-contingent income stream which in part counteracts the negative income shock from husband's unemployment. Such programmes may reduce wife's employment response to husbands unemployment ${ }^{5}$. If transfers are made wholly on an individual basis, as is the case in most UI systems, then there is purely an income effect

3 This is a prediction from the conventional model of family labour supply. Chiappori (1992) and others have developed alternative models based on individual utility maximisation which would not necessarily have this property.

4 See Machin and Waldfogel (1994) and Juhn and Murphy (1996) on the contribution of wife's earnings to household income for the UK and the US respectively.

5 Gruber and Cullen (1996) look at the "crowding out" effect of UI on spousal labour supply in the US. 
on the decisions of other family members ${ }^{6}$. However UA, with its associated family means-testing, will typically impose a high marginal effective tax rate on the earnings of the spouse $^{7}$ (and perhaps other family members too).

The estimation of the impact of household unemployment on spousal labour supply faces several difficulties. Assortive mating may confound empirical estimates of labour supply response. There may be differences in tastes for work of women married to unemployed men relative to women married to employed men. Skills and wage offers may be correlated within families. Furthermore, local labour market conditions may reflect employment opportunities facing the whole family. More generally, there may be a Discouraged Worker Effect (DWE) where wives are less likely to search for work when there is a general economic down-turn since the returns to search fall ${ }^{8}$.

Thus, in our estimates of a labour supply model for married women here, we allow for endogenous husband unemployment duration in order to address the problem of correlation between spouse unobservables. We also accommodate wife unemployment duration so as to distinguish between labour market non-participation and inability to obtain work. This is applied to the UK UI and UA programmes for a sample of married couples. The estimates show that women married to men who have been unemployed for more than 6 months are quite different to other married women in both observable and unobservable ways. The presence of young children has a much stronger influence, and the welfare system (together with low shadow wages) contributes to about half the difference in labour supply behaviour. Simulations suggest that the success of the Job Seeker's Allowance programme depends crucially on its effectiveness in getting husbands back to work. The labour supply disincentives from the welfare system facing women married to men who remain unemployed are made significantly worse by the reform.

\section{Literature}

Most studies of the impact of husband unemployment on wife's work focus on the participation margin. Examples of UK studies are Gomulka and Stern (1990) who estimate participation Probits for wives of employed men from UK Family Expenditure Surveys (FES)

\footnotetext{
6 However, when the budget constraint is non-linear the comparative statics are inevitably more complex. In particular, the kink associated with non-participation causes such complexities.

7 The UK has an intermediate system for UI whereby a spouse addition to the level of entitlement acts like a fixed cost of work, since it is lost as soon as earnings exceed it.

$\mathbf{8}$ Discouraged workers are individuals who would like to work but feel no suitable job is available. Officially they are out of the labour force because they are not actively seeking work (OECD, 1996b). OECD (1995) considers them to be a group of interest in themselves, representing an identifiable element of labour market slack since they can be considered as closer to the labour market than other non-participants.
} 
1970-83 year by year. Garcia (1991) estimates a participation Probit for 946 wives taken from a 1978 UK Cohort Study of the Unemployed and concludes extending UI to UA men would increase participation of wives of unemployed men by $8 \%$. For Germany, Giannelli and Micklewright (1995) use monthly data 1983-87 on 2000 married couples from the German Socio-Economic Panel (GSOEP) to estimate a fixed effect Logit for wife participation. They find that having a husband who is unemployed short-term is only weakly associated with the wife being a non-participant.

A couple of US studies focus explicitly on this issue ${ }^{9}$. Lundberg (1985) estimates a Multinomial Logit on monthly data for transitions between non-participation, employment and unemployment, as a function of exogenous husbands' employment status. She finds a small AWE for white wives: that is when the husband becomes unemployed, the probability of a non-participating wife entering the labour force increases, but the probability of the wife moving from unemployment to employment falls. Maloney (1991) estimates a model of wife's participation and conditional employment as a Bivariate Probit. He attempts to control for potentially transitory observed unemployment by including reisduals from a first stage Probit of husband unemployment in the second stage bivariate Probit, as a proxy for husband's unemployment risk. However, the estimation is misspecified in the second stage which relies on joint normality of second stage error terms only.

The only cross country comparative work is that of Dex, Gustafsson, Smith and Callan (1995). They estimate wives employment Probits given exogenous husband employment status, and find no effect on wife's participation in Denmark and the US but a negative effect in the UK. This is attributed to the UK UI programme which has UI as a function of wife's earnings.

A number of studies address wife's labour supply response to husband's unemployment. For the US, Heckman and MaCurdy (1982) estimate a fixed effect hours Tobit on 672 married women from 1968-75 Panel Study of Income Dynamics (PSID) and find a significant positive effect of husbands unemployment on wife's hours of work, which is consistent with an AWE. Gruber and Cullen (1996) use both Tobit and Heckman selection models for wife's hours on a sample of women with unemployed husbands from the Survey of Income and Program Participation (SIPP) 1984-92 and find only a small effect on wife's labour supply.

In the UK Layard, Barton and Zabalza (1980) estimate a Tobit model for married women's participation and hours using 2200 married couples from the 1974 General Household Survey and find wives of unemployed men have a lower employment probability and lower expected

9 See Moffitt (1992) for a general overview of the US welfare system and its incentive effects. 
hours conditional upon employment. Kell and Wright (1990) estimate a Bivariate Probit for wife's participation and conditional full-time work using 2051 married couples from the 1983 Family Expenditure Survey. Their results are consistent with the incentives implied by the structure of the tax and benefit system as discussed in Dilnot and Kell (1990): women are less likely to work when families receive UA, but hours of work conditional upon participation are greater than the average for the population because the incentive to work part-time is undermined by the UI system due to its dependent's earnings disregard.

Our approach is distinctive from previous work since we consider married women's labour supply together with the possibility that both husband and wife suffer from involuntary unemployment. Furthermore, we analyse the effect of husband's unemployment duration on labour supply, which appears to be the dimension over which married women's labour supply behaviour differs most according to husband unemployment status. We implement a choicebased unordered response model which is appropriate for dealing both with the non-convex budget constraints facing women married to unemployed men and with the wives of the employed. The methodology used enables us to evaluate incentive effects of recent reforms to transfer programmes for the unemployed, while dealing with many of the empirical problems which have dogged previous estimates of the effect of the husband's employment status on the wife's labour supply.

\section{Transfer Programmes for the Unemployed}

The latest UI reforms reduced the maximum duration of transfer receipt from 12 to 6 months, and the programme changed name from Unemployment Benefit to Job Seeker's Allowance $^{10}$ (JSA). A large number of UK studies show that there is a lower probability of leaving unemployment the higher the level of benefits received ${ }^{11}$. However, recent UK evidence suggests that there is a declining effect of unemployment income on the conditional probability of leaving unemployment ${ }^{12}$, and no effect after the fifth (Narendranathan and Stewart (1993))

10 CPAG (1996) gives details of the October 1996 introduction of JSA.

11 See Atkinson, Gomulka, Micklewright and Rao (1984), Narendranathan, Nickell and Stern (1985), Micklewright (1985). Dilnot and Morris (1983) summarize the debate between Atkinson, Gomulka, Micklewright and Rau (1984) and Nickell (1979) about robustness of the empirical relation between UI and unemployment duration.

12 Dilnot and Morris (1983) show that replacement rates rose 1968-78 due to increased taxation and more generous benefits, but fell thereafter. Of interest for the re-employment decision of the unemployed is the marginal replacement rate, which decreases with duration. Abolition of the Earnings Related Supplement to UB, and the taxation of transfer payments have lowered replacement rates for spells up to six months, but not affected longer term ones. 
or sixth month (Narendranathan, Nickell and Stern (1985)) ${ }^{13}$.

If, in the light of the above evidence, the direct effect of JSA on re-employment is small then it may be the case that any direct beneficial effects on work incentives will be outweighed by the deterioration in incentives facing spouses in married couples. The important point is whether husband's unemployment-related benefits are linked to wife's earnings. The most common system of programmes for the unemployed is a UI transfer based on purely individual contributions, supplemented by UA (for those with inadequate UI) which is means tested on the basis of family income. UK UI has a wife's earning allowance, which is completely withdrawn if the earnings of the wife exceed it. The introduction of the JSA means that those who are unemployed 6-12 months are effectively transferred from UI to UA.

Recent changes should be placed in the context of the broader reforms to the tax and benefit system which have occurred during the last 20 years. This emphasizes the growing importance of the incentive issues raised and motivates an evaluation of JSA on the basis of identification of incentive effects from previous welfare reforms occurring during the sample period 1978-92.

During the 80's all transfers to the unemployed have increased in stringency ${ }^{14}$ and have been made taxable (from 1982). The introduction of Job Seeker's Allowance continues a trend away from insurance-related benefits towards reliance on family-income-tested assistance for the unemployed that was highlighted in Atkinson and Micklewright (1989). The majority of the unemployed fail to qualify for UI on grounds of insufficient contributions. In 1986 of the (approximately 3 million) unemployed $27 \%$ had insufficient contributions and $37 \%$ had exhausted their 12 month entitlement and so were reliant on UA.

13 In contrast, US studies indicate the likelihood of an unemployed person leaving unemployment increases modestly in a period before benefit fall (UI exhaustion). Moffitt (1985) finds increasing UI duration by 1 week increases mean duration by 0.1 weeks. Katz and Meyer (1990) find 0.2. However, as Atkinson and Micklewright (1991) point out, the destination could be either employment or non-participation.

14 Atkinson (1995) describes the key institutional features of UI and UA in the UK and US.

Although entitlement levels have effectively been indexed to the retail price index, their level relative to real earnings has fallen. Child additions were removed in 1984. Reduced rate benefits were abolished in 1986 so that those without a full contribution record received no UI rather than a fraction as before. Moreover, from 1982 registration with the public employment agency was required, and from 1988 people were called for "Restart" interviews every 6 months (see Dolton and O'Neill (1995)) and could be denied further UI if they failed to comply with the job search recommendations in the interview. Entitlements for youths have also been linked to training, and supplements for housing costs have been eroded.

Micklewright (1985) discusses the Earnings Related Supplement (ERS) which was the part of UI linked earnings during the last tax year and payable during 2-26 weeks of unemployment. This was subject to a maximum, with additions for dependents. It's last year of full operation was 1980, when $20 \%$ of those unemployed received it and expenditure constituted about $15 \%$ of the UI programme. 
UA entitlements have also deteriorated. UA transfers to married couples were removed if either partner work over 24 hours from 1988. Prior to this, entitlement was reduced on account of partner's earnings but not precluded. This particularly affected couples without children where neither were entitled to Family Credit. Recent UK reforms have had the effect of discouraging single household formation and increasing dependence between family members. The non-householder's rate for UA has been removed and the rate for those under 25 has fallen, in order to encourage people not to leave the parental home until financially independent. The US welfare system provides adverse incentives for the formation of two-parent families ${ }^{15}$.

It is evident that recent UK reforms are consistent with the direction of welfare policy changes since 1978: towards family-based means-tested transfers for the unemployed. This is important since it allows us to use the time series sample variance to assist in the identification of the effect of current reforms on the basis of how individuals have been observed to respond to policy reforms prior to 1992 .

\section{Data}

Our data consist of 15 pooled cross-sections of Family Expenditure Surveys (FES) ${ }^{16}$ from 1978 to 1992 which yields a sample of 43,531 married couples who are householders. We compute eligibility and the level of entitlement from a very detailed routine ${ }^{17}$ that acknowledges all of the features of the tax, welfare and social security contribution systems (except for in-kind transfers) where we base the calculations on estimated wage equations. In this section we shall use the FES data to broadly motivate our study and chosen approach. We conduct a preliminary investigation into the contribution of household employment status to inequality over time; define primary and secondary workers; and show that husband unemployment duration is the appropriate dimension over which to analyse married women's labour supply.

Jenkins (1995) shows that UK Income inequality has increased since the 70's. This is explained by growing earnings dispersion (Gosling, Machin, Meghir (1994)), wage dispersion (Meghir and Whitehouse (1996)), increasing polarisation between dual- and no-earner house-

15 Empirical studies for the US show that the magnitude of the disincentive effects is very small and cannot explain female headship and non-marital child-bearing (Hoynes, 1996c). Current US reforms are for the equal treatment of two-parent families on welfare with the removal of the additional AFDC 100 hours rule.

16 Atkinson and Micklewright (1983) consider the deficiencies of the FES data in detail. It is difficult to use data prior to 1978 because of the absence of schooling information, and data beyond 1992 does not contain appropriate information about housing costs to deal with changes in the local tax system that occurred at this time.

17 The routine is based on the Institute for Fiscal Studies' TAXBEN programme but is less complicated in that it considers only married couples although more complicated in that it considers not just tax-benefits at the observed level of hours but also at other levels, and it deals with all of the changes that have taken place between 1978 and 1992. See Johnson, Stark and Webb (1990) for details of TAXBEN. 
holds (Machin and Waldfogel (1994)) and the increase in benefit-dependent families (Gregg and Wadsworth (1996)) ${ }^{18}$. Indeed, real earnings and hours fell for both men and women in the bottom quintile of both the husband and the married couple income distribution 1978-92, whereas the opposite is true above decile three ${ }^{19}$. This is shown in the Appendix Figures A1 and A2.

\section{Figure 1. Married Couple Employment Status}

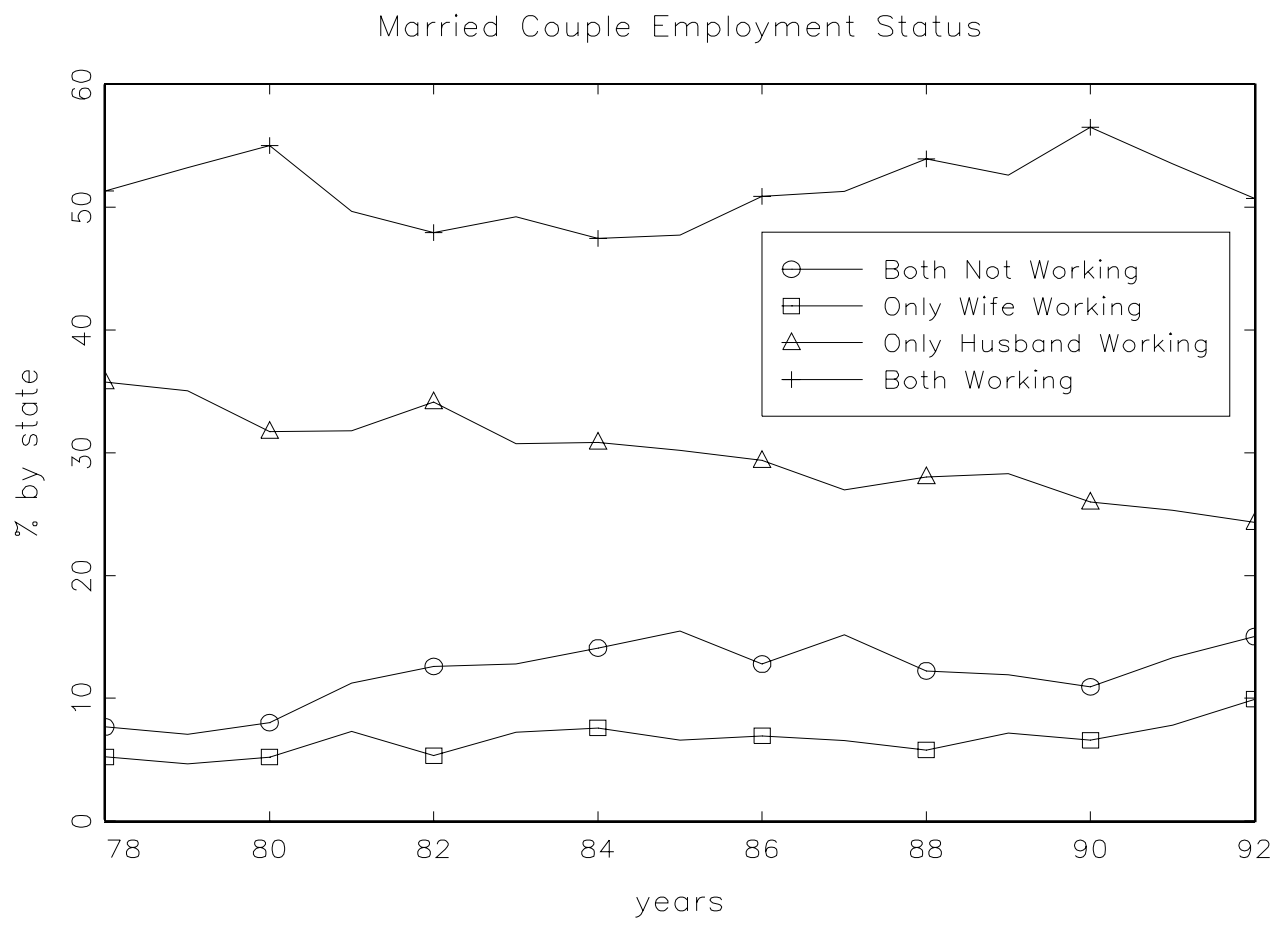

Over the sample period we see an increase in the proportion of married couples with an unemployed husband. Figure 1 shows the evolution of employment status of married couples over time. The trend is for an increasing proportion of couples who are both not working at the expense of couples where only the husband works ${ }^{20}$.

18 It is important not to overstate the extent to which wives contribute to income inequality between couples. Borooah and McKee (1996) and Machin and Waldfogel (1994) find that wives contributed 31 and $27 \%$ to inequality in 1990 and 1993 respectively. Of the change in inequality 1979-93 27\% was due to wives.

19 Juhn and Murphy (1996) tell a similar story in terms of relative movements for the US.

20 Gregg and Wadsworth (1996) look at 13 OECD countries 1983-1994 and find that among two-adult households there is a decline in the proportion where only one partner works. 
Our focus is on wives' response to husbands' unemployment. Despite recent trends in female versus male hours and earnings, we can consider Figure 2 in order to motivate wives as a starting point for examining secondary earners. The top panel shows that for an increasing proportion of couples the wife works most and earns most. However the bottom panel indicates that mean female earnings proportion is about $20 \%$, because of roughly both $50 \%$ lower wages and hours.

Table 1 Household Labour Force Status

\begin{tabular}{cccccccc}
\hline $\begin{array}{c}\text { Husband's } \\
\text { Unemployment } \\
\text { Status }\end{array}$ & \multicolumn{3}{c}{ Labour Supply Decision } & \multicolumn{5}{c}{ Wife's } \\
Unemployment Status & All \\
None & Full-time & Part-time & Non-part & Short & Medium & Long \\
& 10733 & 13326 & 11535 & 496 & 270 & 407 & 36767 \\
& $(29.2)$ & $(36.2)$ & $(31.4)$ & $(1.3)$ & $(0.7)$ & $(1.1)$ & $(100.0)$ \\
Short-term & $(87.7)$ & $(88.3)$ & $(79.0)$ & $(78.2)$ & $(73.2)$ & $(67.1)$ & $(84.5)$ \\
& 1189 & 1370 & 1500 & 100 & 48 & 78 & 4285 \\
& $(27.7)$ & $(32.0)$ & $(35.0)$ & $(2.3)$ & $(1.1)$ & $(1.8)$ & $(100.0)$ \\
Medium-term & $(9.7)$ & $(9.1)$ & $(10.3)$ & $(15.8)$ & $(13.0)$ & $(12.9)$ & $(9.8)$ \\
& 180 & 199 & 486 & 22 & 29 & 19 & 935 \\
& $(19.3)$ & $(21.3)$ & $(52.0)$ & $(2.4)$ & $(3.1)$ & $(2.0)$ & $(100.0)$ \\
Long-term & $(1.5)$ & $(1.3)$ & $(3.3)$ & $(3.5)$ & $(7.9)$ & $(3.1)$ & $(2.1)$ \\
& 139 & 189 & 1075 & 16 & 22 & 103 & 1544 \\
& $(9.0)$ & $(12.2)$ & $(69.6)$ & $(1.0)$ & $(1.4)$ & $(6.7)$ & $(100.0)$ \\
& $(1.1)$ & $(1.3)$ & $(7.4)$ & $(2.5)$ & $(6.0)$ & $(17.0)$ & $(3.5)$ \\
\hline \multirow{2}{*}{ All } & 12241 & 15084 & 14596 & 634 & 369 & 607 & 43531 \\
& $(28.1)$ & $(34.7)$ & $(33.5)$ & $(1.5)$ & $(0.8)$ & $(1.4)$ & $(100.0)$ \\
& $(100.0)$ & $(100.0)$ & $(100.0)$ & $(100.0)$ & $(100.0)$ & $(100.0)$ & $(100.0)$ \\
\hline
\end{tabular}

Note: The figures in parentheses are row and column percentages.

Having shown the growing proportion of married men who are out of work, Figure 3 examines their unemployment duration. While there is some cyclical behaviour in the data, the principal secular changes are the decrease in the proportion who are short-term unemployed (0-6 months) by about a third, which is largely reflected in an increase in long-term unemployment (over 12 months duration). The proportion unemployed longer than six months has doubled. 
Figure 2. Married Women Primary Workers Over Time

Married Women Primary Workers over Time

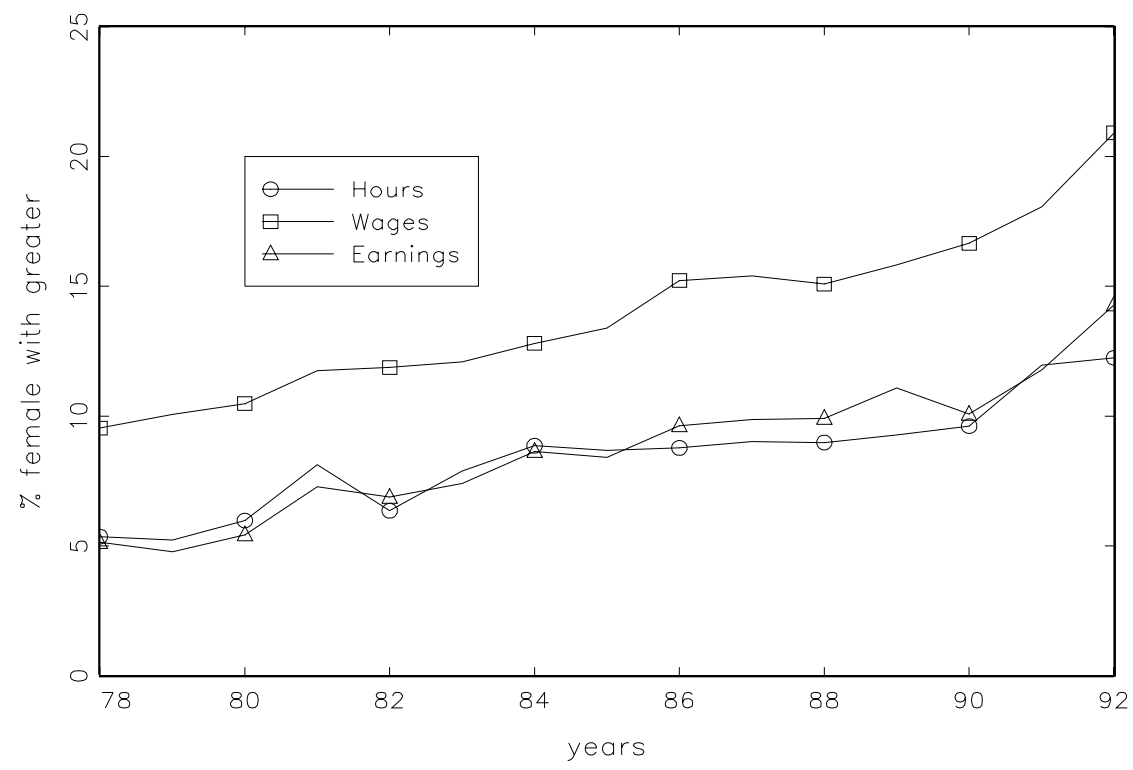

Married Women Primary Workers over Time

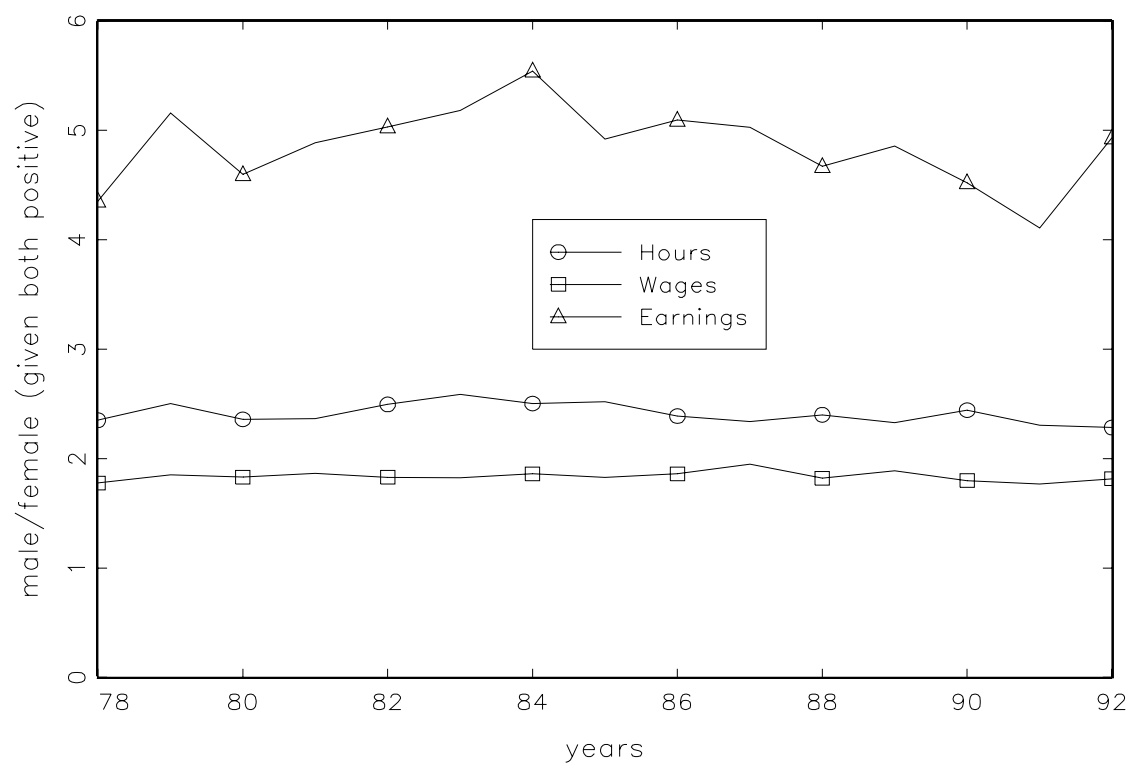


Figure 3 Unemployment Duration of Married Men over Time

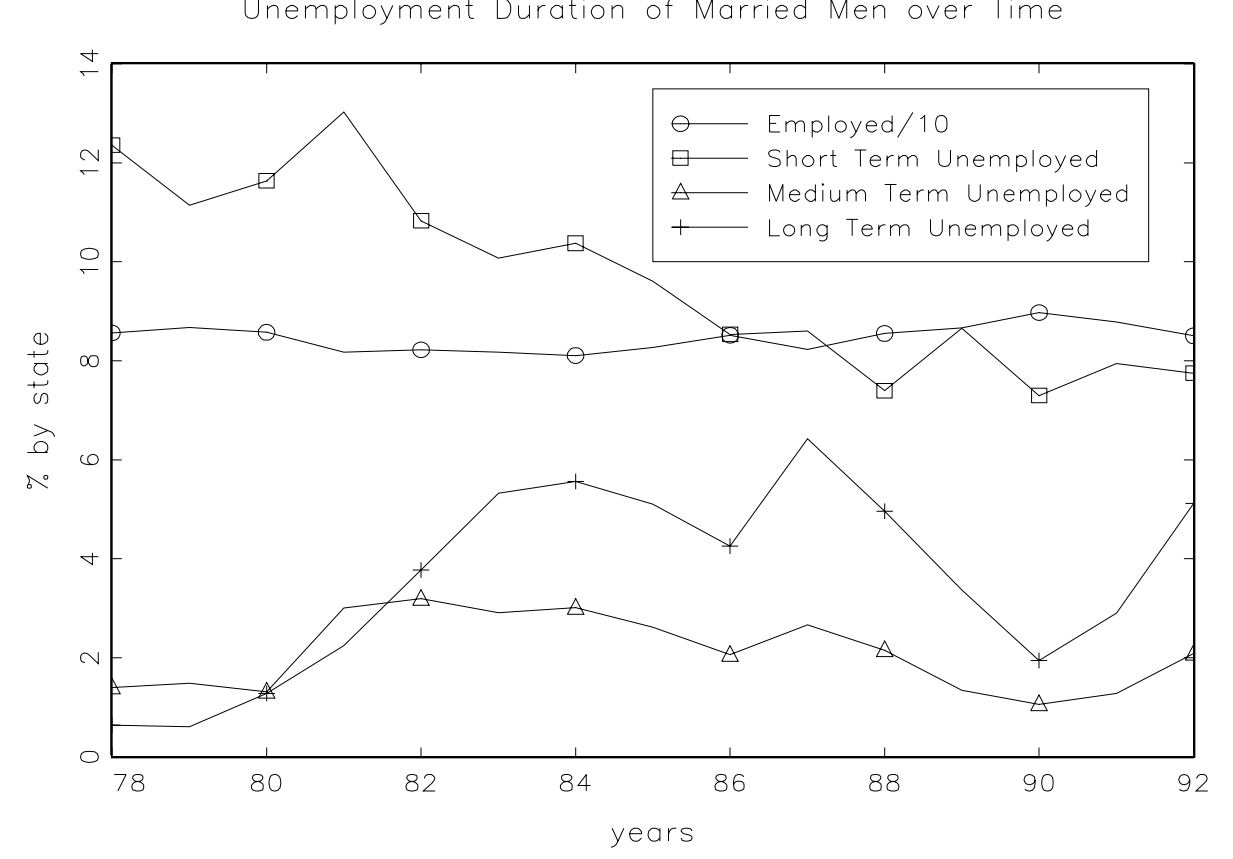

Figure 4 Married Womens Labour Supply by Husband's Employment Status
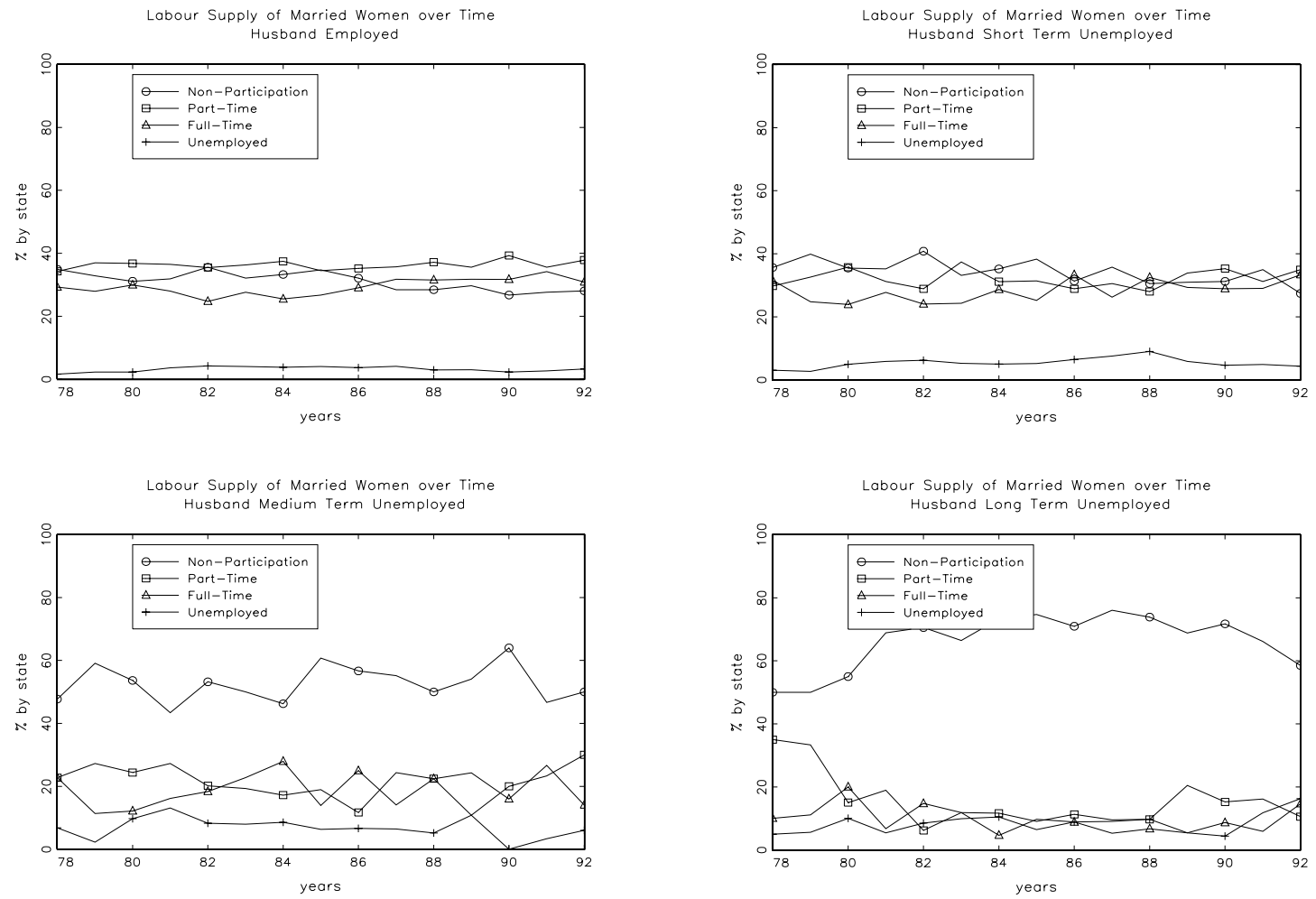
The full decomposition of household employment status is given in Table $1.15 .5 \%$ of married women have an unemployed husband. Of those $6.4 \%$ are themselves involuntarily unemployed and $45.2 \%$ non-participants. The corresponding figures for women with employed husbands are $3.1 \%$ and $31.4 \%$. It is this decomposition that we attempt to model.

The labour supply of wives broken down by husbands' unemployment duration is shown in Figure 4. There appears to be no difference between the labour supply of women with employed husbands and those with short term unemployed husbands. However, the proportion of non-participants for women married to medium-term and long-term unemployed men doubles and trebles respectively.

\section{Econometric Framework}

The budget constraints faced by UK women married to unemployed men are likely to take a complicated piecewise-linear form with several important non-convexities ${ }^{21}$. Moreover, we find strong evidence that there is non-convexity in the gross budget constraint induced by a marked differential between the wages of full-time workers and part-time workers which may be due to the incidence of the pay-roll tax system or because of fixed costs in the production process. There are severe difficulties associated with estimating a labour supply model that allows for the possibility of continuous hours substitution ${ }^{22}$ in the face of such complex budget constraints. Our approach follows much of the literature on modelling the labour supply of low income households and approximates the continuous choice with a choice among discrete alternatives $^{23}$. Each regime is characterised by some specific hours level. Individuals choose between these alternatives and no hours substitution is allowed within regimes. Though obviously an approximation, one could argue that choice between discrete hours offers is an empirical regularity, and modelling a continuous choice may, in fact, be a mis-specification.

21 Mother face one non-convexity due to the Family Credit (FC) notch at 24 hours interacting with the $100 \%$ tax faced by those on IS, and another arising from FC eligibility ceasing as earnings rise. Women without children are ineligible for FC and face a fall in net income at the IS 24 hours limit. Regardless of the presence of children there exists a notch at the lower earnings limit for National Insurance contributions.

22 MaCurdy, Green and Paarsch (1990) take an approach which is based on estimating an hours equation where the budget constraint is approximated by a quadratic. However, the possibility of finding a suitable reasonable approximation to the constraint faced by UK women married to unemployed men. A second approach can be found in Blundell, Duncan and Meghir (1993) where they sidestep the problem by taking a "deep selection" of high earning women only and correcting for the resultant bias using some reduced form. The weakness of this approach is the absence of convincing exclusion restrictions to achieve identification.

23 Zabalza, Pissarides and Barton (1980) characterise the choice over retirement, part-time or full-time work as an ordered probit with random parameters. They can do this because their sample exhibit kinked but convex budget sets. Moffitt (1984) estimates a discrete choice model where their is gross wage endogeneity which is modelled as a quadratic relationship between wages and hours. Hoynes (1996a) is a recent example. 
McFadden (1984) surveys the discrete response literature and motivates a choice of modelling framework appropriate to the present context following Hausman and Wise (1978). That is, we estimate an unordered Probit random utility model over three states (full-time work, part-time work and non-participation) and we control for the fact that some of those working zero hours would rather be working. Since these choices are determined by the income levels associated with each state, and we only observe one of these, we need to predict incomes for each state from the income in the observed state. Since it would be computationally burdensome to estimate the wages associated with each state jointly with the choice of state, and since we only require consistent prediction of wages in order to estimate the determinants of each state, we adopt a two-step procedure. In the first step we estimate full-time and part-time wage equations which use a reduced form for labour market status to control for the endogeneity of labour market status and use these estimates to predict incomes in the part-time and full-time positions. Income for non-participants is computed from a knowledge of the welfare system and observed unearned (non-transfer) income. In the second step, we estimate the random utility model using the predicted income in each state.

Identification of the first step reduced form Probit on labour force status is through functional form alone. In the first stage labour supply model we include unearned income which is excluded from the wage equation and schooling is included in the wage but not in the labour supply model. Moreover, while the labour supply model includes year dummies, identification does exploit the wide real variation in welfare entitlements over time, partly driven by real variations in housing costs.

We approximate the budget constraint by just three discrete points which we think of as labour market non-participation (NP), part-time work (PT) and full-time work (FT) ${ }^{24}$. The choices between the three alternatives are assumed to be driven by differences in the utility attached to them. Let the utility associated with choosing state $k$ be $U_{i}\left(y_{k}, h_{k} ; X\right)$ where $y_{k}$ is the income and $h_{k}$ the hours associated with this choice and $X$ is a vector of individual characteristics.

24 We define these as: usual weekly hours $0,1-30,31+$ respectively. We then compute their incomes at $0,24,40$ hours. An important criticism of discrete choice modelling is the arbitrary nature of the definition of the alternatives. Sensitivity of the estimates to different definitions of what constitutes the regimes may be tested. 
Now consider a statistical specification ${ }^{25}$ which allows for random variation in behaviour due to an additive disturbance and variation in $\operatorname{tastes}^{26}, U_{i}^{*}\left(y_{k}, h_{k} ; X, \varepsilon_{k}\right)$, where $U_{i k}^{*}$ is unobservable utility of state $k$ for individual $i$. Thus, the utility gain of moving from alternative $k$ to $j$ is

$$
U_{i}^{*}\left(y_{j}, h_{j} ; X, \varepsilon_{j}\right)-U_{i}^{*}\left(y_{k}, h_{k} ; X, \varepsilon_{k}\right) \equiv U_{i j}-U_{i k},
$$

where the subscript $i$ denotes the individual, while $j, k$ denote alternatives. In a discrete choice model the choices $j$ and $k$ are assumed to be common across $i$ so this utility difference can be expressed as

$$
U_{i j}^{*}-U_{i k}^{*}=g\left(y_{i j}, y_{i k}\right)\left(\bar{\psi}+\tilde{\psi}_{i}\right)+X_{i} \omega_{j k}+\left(\varepsilon_{i j}-\varepsilon_{i k}\right),
$$

where $g\left(y_{i j}, y_{i k}\right)$ is a row vector of differences of functions of the net incomes, and $\bar{\psi}$ reflects the mean tastes of the sample while $\tilde{\psi}_{i}$ is a coefficient vector which shows how $i$ differs from the mean, and $\left(\varepsilon_{i j}-\varepsilon_{i k}\right)$ is an additive disturbance assumed to be iid across $i$ but not necessarily across $j^{27}$. The choice of $g()$ is arbitrary, although here we assume linearity for simplicity.

Keeping a linear form in $\psi$ enables us to introduce random parameters as described in Hausman and Wise (1978). In this case assuming that the error terms are distributed multivariate normal and that the parameters are distributed independent normal is a natural choice and leads to tractable expressions for the probabilities. The model thus obtained belongs to the class of Multinomial Probit Random Utility Models.

As usual in this class of model only the utility differences between the number of alternatives minus one can be identified ${ }^{28}$. It is possible to interpret the parameters $\omega_{j k}$ as a gain (or a loss) in utility from having the characteristics $X_{i}$ when one compares the alternative $j$ to the alternative $k$, where the latter choice is the reference.

From (2) the probability of observing $i$ in state $j$ is given by

25 Fischer and Nagin (1981) denote this a random coefficients, co-varying disturbances model.

$26 \varepsilon_{h i}$ could represent unobserved attributes of alternatives or individuals which affect choice but are uncorrelated with $V_{h i}$. This may also be a pure element of random choice. Note that, by itself, an additive disturbance term allows no variation in tastes. Individuals with identical observables may have different tastes, and this variance must be incorporated explicitly in the taste parameter. It can easily be shown that failure to incorporate taste variation induces a downward bias to estimates of taste parameters.

27 Hausman and Wise (1978) assume $\varepsilon_{h i}$ to be iid across alternatives too.

28 See Pudney (1989) for a discussion. 


$$
\begin{aligned}
P_{i j} & =\operatorname{Pr}\left[U_{i j}^{*}>U_{i k}^{*}\right] \\
& =\operatorname{Pr}\left[g\left(y_{i j}, y_{i k}\right)\left(\bar{\psi}+\tilde{\psi}_{i}\right)+X_{i} \omega_{j k}>\left(\varepsilon_{i j}-\varepsilon_{i k}\right)\right] \quad \forall j \neq k .
\end{aligned}
$$

The FES asks those with zero hours in the labour market whether they are actively looking for a job and we use this information to discriminate between voluntary non-participation and involuntary unemployment ${ }^{29}$. This is important because women who are involuntarily unemployed are not observed to be in their most preferred state, and must be classified appropriately in a choice model. For the purposes of labour supply modelling this group is assumed to reveal that some positive hours state is preferred to zero. Furthermore individuals observed in any positive hours labour market state are assumed to prefer their observed state to all alternatives and are not rationed in exercising this preference.

Moreover we know how long each person has been out of work during the current spell. For women this information is used conditional upon seeking work in order to distinguish true non-participants. For men this information is used unconditionally ${ }^{30}$. We use the generic term unemployment for both men and women ${ }^{31}$. The unemployed are discretized according to duration: short-term (ST), medium term (MT) and long-term (LT) ${ }^{32}$. These are determined by the following latent and observed unemployment rationing equations

29 Blundell et al (1987) also exploit the availability of this information. We cannot use observed receipt of unemployment benefits since many (older) women in the data have been able to opt to pay social security contributions at a reduced rate which does not provide them with a right to unemployment benefit.

30 Of those out of work the proportion of seekers is 95.7 and 10.0\% for men and women respectively (including 7.9 and $0.9 \%$ who are ill but intending to seek). The non-seekers are partitioned into 1.9 and $1.7 \%$ retired; 1.2 and $3.5 \%$ ill and not intending to seek; 1.2 and $84.8 \%$ unoccupied.

31 Men who are out of work but not seeking may be ill (in receipt of statutory sick pay or sickness benefit), disabled (receiving invalidity allowance), in need of care (receiving attendance allowance or disability living allowance), or retired (retirement pensioners are too old to be in our sample). See Appendix Table 8 for transfer programme participation among out of work men. Disney and Webb (1991) document the growing importance of tranfers to the disabled in Britain.

32 These durations are months $\leq 6,6<$ months $\leq 12,12<$ months. They correspond to the time limits on the different unemployment transfer programmes. Short-term transfers are or were JSA, ERS, sickness allowance and statutory sick pay. Short and medium-term was UB. Medium and long-term is invalidity allowance. Long-term (in any instance and earlier according to circumstance) is income support. Programme participation descriptives in the Appendix Table 8 show that duration away from work corresponds to observed transfer receipt quite well as would be expected according to eligibility rules. 


$$
\begin{aligned}
R_{i}^{s^{*}} & =Z_{i}^{s} \tau^{s}+v_{i}^{s} \\
R_{i}^{s} & =\left\{\begin{array}{lll}
0 & \text { if } & R_{i}^{s^{*}} \leq 0 \\
S T & \text { if } & 0<R_{i}^{s^{*}} \leq \mu_{1}^{s} \\
M T & \text { if } & \mu_{1}^{s}<R_{i}^{s^{*}} \leq \mu_{2}^{s} \\
L T & \text { if } & \mu_{2}^{s}<R_{i}^{s^{*}}
\end{array}\right.
\end{aligned}
$$

where $R_{i}^{s^{*}}$ is the latent variable corresponding to the observed rationing, $R_{i}^{s}$, of couple $i$, spouse $s . Z_{i}^{s}$ is a matrix of demand side variables; $\tau^{s}$ is a corresponding vector of parameters; and $v_{i}^{s}$ is a random error ${ }^{33}$. Details concerning stochastic specification, identification and likelihood contributions are relegated to an appendix.

\section{Estimates}

Model estimates are presented in Table 2 to give an idea of sign, magnitude and significance. The direct interpretation of comparison-specific parameters in an unordered model is less than transparent since the alternative-specific coefficients (on the alternative-invariant variables) tell us about the impact of characteristics on the probability of choosing one state rather than the default (of voluntary non-participation). A positive sign implies that a variable is associated with increasing the probability of being in the destination state. For example, a positive coefficient on renter in the $F T \rightarrow N P$ equation means that living in rented accommodation makes one more likely to prefer NP than $F T$.

The interpretation of the coefficients on alternative-specific variables (income) is more direct. This measures the impact of the difference in the variable between states on the probability of being in any state. The positive coefficient $\bar{\psi}$ on the income difference means that more income is preferred to less. As well as estimating the mean of the income difference coefficient, the variance $\tilde{\psi}$ is estimated to allow for taste heterogeneity. This is appropriate as it appears to

33 The specification for the determination of female wages is $\log W_{i}^{w j}=Y_{i}^{w} \gamma^{w j}+e_{i}^{w j}$, for $j=P T, F T$ where $P T$ and $F T$ indicate part-time and full-time labour force status. We are simply interested in obtaining consistent wage predictions so, although employment status is likely to be endogenous to the wage, we estimate the wage equations by including the Mills Ratios from a Bivariate Probit model of participation $v s$ non-participation and full-time $v s$ part-time work conditional upon participation. We include the level of unearned income in the reduced form labour force status equations but not in the wage equations to achieve identification. Details are available on request.

34 It should be pointed out that mean and variance of the wife's predicted wages, at both part-time and full-time, fall with husband unemployment duration (see Appendix Table 6). The falls in mean part-time predicted wage are $£ 0.17,0.22,0.06$ per week respectively from husband employed to husband ST, MT, and to LT. Women with the lowest skills and shadow wages appear to be married to men who have been unemployed for more that 6 months. 
be supported by the model. Moreover, significant correlations between unobservables in the choice equations suggests that a Multinomial Probit would dominate a more restrictive multinomial logit, whereby comparisons are assumed independent.

A number of estimated coefficients are worth remarking on at face value. Children of all ages deter full-time work, but to a lesser extent as they get older. Having a youngest child at secondary school increases part-time work. A short-term unemployed husband makes no difference to wife's labour supply. However, longer durations have the increasingly strong effect of reducing both full-time and part-time work. Husband employment status is found to be endogenous $^{35}$. In particular unobservables associated with having an unemployed husband are correlated with unobservables reducing the probability of part-time work (but increasing fulltime work and non-participation). This suggests that focussing on the participation margin may be inappropriate as, even after controlling for endogeneity, it would only reveal the net effect which is of ambiguous sign. There are several sets of unobservables which are consistent with this result. Our tax-benefit calculations may not be picking up the disincentives for part-time work for women married to long term unemployed men.

A more transparent way to examine the implications of the estimated parameters is to choose a family as being representative of a group of interest and simulate the effects of changing some of its characteristics. Such a simulation exercise is performed in Table 3. The representative family has median or modal values for all characteristics. The family has weekly income (in 1992 prices) of $£ 159,213,251$ at NP, PT, FT respectively, lives in rented accommodation, has a youngest child at primary school (aged 5-10), faces a local unemployment rate of 5\%, and lives in the South East in 1992. Both husband and wife are aged 29, having left school at age 16.

The simulated probabilities reveal some interesting behaviour. Effects of the economic variables accord with the theoretical predictions. Labour supply is somewhat less elastic at high than at low hours, which is consistent with results in Blundell, Duncan and Meghir (1992) and with the view that incentive effects may be predominantly participation effects (Heckman, 1993). The wage elasticity at low hours increases with husband's unemployment duration.

35 A model with exogenous rationing for husband's unemployment provided starting values for the full model. The likelihood value is significantly increased, as can be seen from considering the likelihood ratio test statistic, $\lambda$, which is defined as $\lambda=-2\left(\ln L_{\rho_{\varepsilon, v}=0}-\ln L_{\rho_{\varepsilon, v}}=\hat{\rho}_{\varepsilon, v}\right)=-2 \times(71280-71360)=160 \sim \chi_{(116-2)}^{2}$. This has a value of 0.00293 . Hence we can reject the restriction of husband unemployment duration exogeneity. 
Table 2 Labour Supply with Endogenous Unemployment Duration

\begin{tabular}{|c|c|c|c|c|}
\hline \multirow{3}{*}{$\begin{array}{l}\text { Spouse } \\
\text { Equation } \\
\text { Variable }\end{array}$} & \multicolumn{2}{|c|}{ Wife } & \multirow{3}{*}{$\begin{array}{c}\text { Wife } \\
\text { Ration }\end{array}$} & \multirow{3}{*}{$\begin{array}{c}\text { Husband } \\
\text { Ration }\end{array}$} \\
\hline & \multicolumn{2}{|c|}{ Choice } & & \\
\hline & $P T \rightarrow N P$ & $F T \rightarrow N P$ & & \\
\hline Intercept $_{0}$ & $0.4105(0.1926)$ & $-1.7750(0.6550)$ & $2.1808(0.1035)$ & $1.9832(0.0640)$ \\
\hline Intercept $_{1}$ & & & $0.2244(0.0115)$ & $0.2422(0.0078)$ \\
\hline Intercept ${ }_{2}$ & & & $0.4817(0.0149)$ & $0.8418(0.0120)$ \\
\hline Age & $-5.9911(0.4241)$ & $0.1837(1.3173)$ & $3.7276(0.3323)$ & $6.2570(0.5739)$ \\
\hline $\mathrm{Age}^{2}$ & $1.4359(0.1012)$ & $1.3979(0.3422)$ & $-0.7204(0.0647)$ & $-1.2251(0.1303)$ \\
\hline Education & & & $1.0920(0.1163)$ & $0.1292(0.2193)$ \\
\hline Education $^{2}$ & & & $-0.0693(0.0127)$ & $0.0054(0.0251)$ \\
\hline Child 0-4 & $0.6173(0.1252)$ & $2.8738(1.0759)$ & $-0.2761(0.0229)$ & $-0.6311(0.0368)$ \\
\hline Child 5-10 & $-0.0030(0.0959)$ & $1.8387(0.7706)$ & $-0.2160(0.0238)$ & $-0.1791(0.0406)$ \\
\hline Child 11-18 & $-0.1835(0.0515)$ & $0.7412(0.3567)$ & $-0.0887(0.0226)$ & $-0.0123(0.0403)$ \\
\hline $\mathrm{R}^{\mathrm{h}}$ short term & $-0.0144(0.1011)$ & $0.2756(0.2117)$ & & \\
\hline $\mathrm{R}^{\mathrm{h}}$ medium term & $0.3429(0.1338)$ & $0.7155(0.3272)$ & & \\
\hline $\mathrm{R}^{\mathrm{h}}$ long term & $0.6859(0.1664)$ & $1.3097(0.5289)$ & & \\
\hline Unemployment & $0.2322(0.0607)$ & $0.1459(0.0893)$ & $-0.4657(0.0587)$ & $-0.3300(0.1076)$ \\
\hline Renter & $0.0219(0.0234)$ & $0.0854(0.0476)$ & $-0.4077(0.0196)$ & $-0.2000(0.0343)$ \\
\hline North & $-0.1747(0.0539)$ & $0.1979(0.1397)$ & $0.0523(0.0531)$ & $0.0412(0.0958)$ \\
\hline Yorkshire & $-0.1594(0.0425)$ & $0.3008(0.1695)$ & $0.0175(0.0400)$ & $-0.0449(0.0704)$ \\
\hline N. West & $-0.2261(0.0429)$ & $-0.0205(0.0718)$ & $0.0326(0.0433)$ & $-0.0042(0.0768)$ \\
\hline E. Midlands & $-0.1142(0.0380)$ & $0.1411(0.0987)$ & $0.0431(0.0384)$ & $0.0093(0.0668)$ \\
\hline W. Midlands & $-0.1256(0.0404)$ & $0.1159(0.0920)$ & $0.0576(0.0407)$ & $-0.0036(0.0744)$ \\
\hline E. Anglia & $-0.1318(0.0469)$ & $0.2990(0.1667)$ & $0.1354(0.0489)$ & $-0.0285(0.0812)$ \\
\hline S. West & $-0.1037(0.0390)$ & $0.2763(0.1464)$ & $0.0874(0.0390)$ & $-0.0938(0.0648)$ \\
\hline Wls,Scot,NI & $-0.0751(0.0435)$ & $0.0952(0.0829)$ & $0.1006(0.0442)$ & $-0.0290(0.0787)$ \\
\hline S. East & $-0.1073(0.0308)$ & $0.1682(0.1014)$ & $0.0640(0.0310)$ & $0.0200(0.0535)$ \\
\hline $1979-80$ & $-0.0986(0.0321)$ & $0.0055(0.0511)$ & $-0.0093(0.0366)$ & $-0.1084(0.0690)$ \\
\hline $1981-82$ & $-0.1617(0.0424)$ & $0.0166(0.0713)$ & $-0.0090(0.0449)$ & $-0.2751(0.0830)$ \\
\hline $1983-84$ & $-0.2601(0.0515)$ & $-0.0688(0.0776)$ & $-0.0090(0.0534)$ & $-0.2228(0.0992)$ \\
\hline $1985-86$ & $-0.2069(0.0527)$ & $-0.0634(0.0776)$ & $0.2078(0.0542)$ & $-0.1343(0.1009)$ \\
\hline $1987-88$ & $-0.2478(0.0434)$ & $-0.2545(0.0864)$ & $0.1639(0.0441)$ & $-0.1420(0.0820)$ \\
\hline $1989-90$ & $-0.1996(0.0378)$ & $-0.2175(0.0781)$ & $0.2355(0.0396)$ & $-0.0417(0.0732)$ \\
\hline 1991-92 & $-0.1866(0.0381)$ & $-0.2807(0.1008)$ & $0.1071(0.0393)$ & $-0.1536(0.0722)$ \\
\hline $\bar{\psi}$ & 1.372 & $0.4425)$ & & \\
\hline$\tilde{\psi}$ & 0.08 & $0.0410)$ & & \\
\hline$\rho_{\varepsilon, v^{h}}$ & $0.0732(0.0360)$ & $-0.1385(0.0630)$ & & \\
\hline$\rho_{\varepsilon, \varepsilon}$ & 0.24 & $0.0426)$ & & \\
\hline$\sigma$ & 1 & $1.9182(1.4955)$ & 1 & 1 \\
\hline $\begin{array}{l}\text { Log Likelihood } \\
\text { Observations }\end{array}$ & & & & \\
\hline
\end{tabular}

Note: Standard errors are in parentheses. The reference categories are no children, an employed husband, owner-occupier (including mortgagees), Greater London and 1978. Note that age is defined as true age less 17, and education is school leaving age less 14 . All continuous variables (income, age, education, unemployment rate) are scaled to have a mean between zero and one. See Appendix Tables 5 and 6 for a full set of descriptives.

The age of youngest child has the strongest effect on labour supply. Women without children, all else equal, have a 74\% participation probability regardless of husband employment status. The presence of a pre-school child reduces participation by 43 and 55\% for those with employed and unemployed husbands respectively. The greatest difference according to husband status occurs when the youngest child moves to secondary school. Participation increases more 
for women with unemployed husbands. In the absence of children this difference is greater still. The presence of children who need looking after appears to restrict women with an unemployed husband to a greater extent. This may suggest they are unable to afford as much child care, since the husband lacks earnings and her own net wage is much lower. Furthermore, unemployment rationing is higher for women with a pre-school child, as the number of suitable job offers becomes more limited due to care commitments.

Discouraged workers are accounted for by the regional monthly unemployment rate. A $1 \%$ increase in this reduces wife's employment by $0.8 \%$, three quarters of which is due to discouragement. As expected, this effect is stronger for women with an unemployed husband.

Table $3 \quad$ Selected Simulations (\% expected in each state)

\begin{tabular}{|c|c|c|c|c|c|c|c|c|}
\hline \multirow[t]{2}{*}{ Variable } & \multicolumn{4}{|c|}{$\mathrm{R}^{\mathrm{h}}$ None } & \multicolumn{4}{|c|}{$\mathrm{R}^{\mathrm{h}}$ Medium term } \\
\hline & FT & $\mathrm{PT}$ & NP & UE & FT & PT & NP & UE \\
\hline Reference & 26.04 & 46.78 & 23.39 & 3.80 & 24.17 & 33.50 & 39.32 & 3.00 \\
\hline Income $_{\mathrm{NP}}+£ 10$ & -0.78 & -1.79 & 2.70 & -0.13 & -0.94 & -2.09 & 3.20 & -0.17 \\
\hline Income $_{\mathrm{PT}}+£ 10$ & -0.94 & 2.39 & -1.52 & 0.07 & -0.78 & 2.43 & -1.74 & 0.09 \\
\hline Income $_{\mathrm{FT}}+£ 10$ & 1.59 & -0.97 & -0.65 & 0.03 & 1.56 & -0.68 & -0.93 & 0.05 \\
\hline Owner & 2.76 & -0.49 & -1.03 & -1.24 & 4.16 & -1.56 & -1.65 & -0.95 \\
\hline $\mathrm{Age}_{\mathrm{w}}+10$ & -10.85 & 10.68 & 1.55 & -1.37 & -10.39 & 8.72 & 2.81 & -1.13 \\
\hline $\operatorname{Age}_{\mathrm{h}}+10$ & 0.24 & -0.23 & -0.01 & 0.00 & 0.65 & -0.56 & -0.09 & 0.00 \\
\hline Education $_{\mathrm{w}}+2$ & 0.06 & 0.10 & 0.05 & -0.20 & 0.04 & 0.06 & 0.07 & -0.16 \\
\hline Education $_{\mathrm{h}}+2$ & 0.35 & -0.34 & -0.02 & 0.00 & 0.97 & -0.83 & -0.14 & 0.01 \\
\hline Unemp' $+1 \%$ & -0.18 & -0.64 & 0.60 & 0.22 & -0.35 & -0.54 & 0.73 & 0.16 \\
\hline Child 0-4 & -14.41 & -13.47 & 26.25 & 1.64 & -14.44 & -13.91 & 27.89 & 0.46 \\
\hline Child 11-18 & 26.10 & -12.64 & -12.81 & -0.64 & 27.35 & -8.16 & -19.03 & -0.16 \\
\hline No Children & 47.73 & -30.06 & -17.10 & -0.57 & 49.37 & -22.06 & -27.36 & 0.04 \\
\hline
\end{tabular}

Note: The likelihood is evaluated for each representative at the estimated parameter values. Confidence intervals for the simulations are not presented. These are created by perturbating the parameters of interest according to their estimated variance, and show only house ownership status is occasionally insignificant at the 5\% level. Unemployed women are grouped together (UE) for the purposes of exposition regardless of duration. Their respective probabilities obtained from the simulation are just summed. Simulations for ST and LT unemployed husbands are presented in Appendix Table 7.

Having examined in detail the properties of the model, and found them to be consistent with our theoretical priors, we now proceed to simulate the recent UI reform and the introduction of the Job Seeker's Allowance. Table 4 presents the results of two simulation exercises conducted on a sample of households with a medium-term unemployed husband. The reference case is where a medium term unemployed husband has no earned income and receives UI. The first simulation involves the move to JSA without any husband employment effects. For the sake of exposition we shall denote this as a move from UB to IS $(U B \rightarrow I S)$ for our population of 
interest. The second simulation involves the husband finding a job ${ }^{36}$. The effects of his employment can be decomposed into a "pure" tax-benefit system effect (by only changing the budget constraint accordingly, denoted $Y^{h} \uparrow$ ) and to an "employed husband" effect per se (by changing his employment status indicator, denoted $R^{h} \rightarrow 0$ ).

Table $4 \quad$ JSA Reform Simulation (\% expected in each state)

\begin{tabular}{lrrrr}
\hline $\begin{array}{l}\text { Reference } \\
\text { Reform }\end{array}$ & FT & PT & State & \multicolumn{1}{c}{ UE } \\
\hline$U B, Y^{h}=0, R^{h}=M T$ & $26.28(0.68)$ & $27.35(0.36)$ & $40.93(0.55)$ & $5.43(0.10)$ \\
$U B \rightarrow I S$ & $1.41(0.96)$ & $-4.49(0.49)$ & $3.48(0.85)$ & $-0.40(0.13)$ \\
$Y^{h} \uparrow$ & $3.27(0.98)$ & $3.06(0.52)$ & $-6.38(0.78)$ & $0.05(0.14)$ \\
$Y^{h} \uparrow, R^{h} \rightarrow 0$ & $8.96(0.95)$ & $2.34(0.54)$ & $-12.54(0.67)$ & $1.24(0.17)$ \\
\hline
\end{tabular}

Note: Standard deviations in parentheses. All (935) families with a medium-term unemployed husband throughout the sample period were timed forward to October 1996. This involved reflating all monetary values (housing costs, unearned income, predicted wage rates) by the appropriate index. Taxes and benefits were computed immediately pre- and post-reform.

If the husband does not find a job, the move to income support reduces participation by $3.5 \%$, mainly at the expense of part-time work. If he finds work, the pure welfare system effect is to increase both part-time and full-time work by about $3.1 \%$. The full effect is a $9.0 \%$ increase in full-time work, and a $1.2 \%$ increase in involuntary unemployment as more women want to work than there are suitable jobs available. All the labour supply effects of the reform are insignificant since the standard deviations in the change in probabilities are quite small.

These results suggest that the impact of the JSA reform on wife's labour supply depends crucially on its effect on husband's employment. The labour supply disincentive for women with husbands who remain unemployed have clearly been accentuated by the reform.

The importance of the costs of child care to the labour supply decisions of wives of unemployed men has been indicated. Recent Family Credit (FC) reforms allow some childcare

36 We need to predict a wage rate for husbands who are currently unemployed, in order to calculate employment earnings at 40 hours and run the tax-benefit system. The specification for the determination of male wages is similar to that used for female wages $\log W_{i}^{h j}=Y_{i}^{h} \gamma^{h j}+e_{i}^{h j}$, for $j=R T, O T$ where $R T$ and $O T$ indicate regular-time (hours 1-44) and over-time (hours 45+) labour force status. We are simply interested in obtaining consistent (regular hours) wage predictions so, although employment status is likely to be endogenous to the wage, we estimate the wage equations by including the Mills Ratios from a Bivariate Probit model of Employment $v s$ unemployment and over-time $v s$ regular-time work conditional on employment. We include the level of unearned income in the reduced form labour force status equations but not in the wage equations, and education only in the wage to achieve identification. Details are available on request. 
costs to be deducted from assessed income, but only if both parents work ${ }^{37}$. The proposed extension of FC to include non-parents will mostly affect couples containing an unemployed husband $^{38}$. This has weaker justification in terms of labour supply incentives than increasing entitlement to those with young children, who are at the moment least likely to work.

\section{Conclusion}

This paper has been concerned with estimating a model of married women's labour supply and husbands' and wive's unemployment duration for married couples in the UK. The novel features of the modelling are that we allow husband unemployment to be endogenous, and we discriminate between non-participants and the involuntarily unemployed. These are important to overcome many of the difficulties which have dogged previous analyses of the differential labour supply of married women according to husbands' employment status; and treating all non-workers as being on their labour supply curve would exaggerate welfare system disincentives.

We find that husband's unemployment is negatively correlated with unobservables associated with part-time work and positively correlated with unobservables associated with full-time work. This suggests that focussing on the participation margin alone, as the added worker effect literature does, is likely to miss important behavioural effects. The discouraged worker effect operates through the (regional) unemployment rate: we find that a $1 \%$ increase in the unemployent rate generates a $0.8 \%$ decrease in participants - three quarters of whom are discouraged.

We find that wives are most different if the husband has been unemployed for over 6 months. Young children have a much stronger influence on the labour supply of women married to unemployed men. About half of the difference in labour supply behaviour is explained by the welfare system together with low skills and shadow wages. Our simulations suggest that the success of the Job Seeker's Allowance reform on wife's labour supply depends crucially upon its effect on husband's employment. The disincentives to labour supply for women with husbands who remain unemployed have been exacerbated.

37 Costs of childcare by a registered childminder or childcare scheme up to $£ 40$ per week may be deducted from assessed income for FC, HB and Disabled Workers Allowance (DWA) from 1994. Both parents must work at least 16 hours a week, unless one is disabled.

38 DSS (1995) gives details of the "Employment Top-Up" pilot extension of the FC programme. 


\section{References}

Ashenfelter, Orley and James Heckman (1974), The Estimation of Income and Substitution Effects in a Model of Family Labour Supply, Econometrica, 42, 73-85.

Atkinson, Tony (1995) Incomes and the Welfare State, Oxford University Press.

Atkinson, Tony, Joanna Gomulka, John Micklewright and Nicholas Rau, (1984) Unemployment Benefit, Social Security and Incentives in Britain, Journal of Public Economics, 23, 2-26.

Atkinson, Tony, and John Micklewright, (1983) On the Reliability of Income Data in the Family Expenditure Survey 1970-77, Journal of the Royal Statistical Society, Series A, 146:1, 33-53.

Atkinson, Tony, and John Micklewright, (1989) Turning the Screw: Benefits for the Unemployed 1979-88, in Andrew Dilnot and Ian Walker (eds.) The Economics of Social Security, Oxford University Press.

Atkinson, Tony, and John Micklewright, (1991) Unemployment Compensation and Labor Market Transitions: A Critical Review, Journal of Economic Literature, 29, 1679-1727.

Blundell, Richard, Alan Duncan and Costas Meghir (1992), Taxation in Empirical Labour Supply Models: Lone Mothers in the UK, Economic Journal, 102, 265-278.

Blundell, Richard, Alan Duncan and Costas Meghir (1993), Tax Policy Reforms and the Robust Estimation of Labour Supply Responses, IFS Working Paper, ??.

Blundell, Richard, John Ham and Costas Meghir (1987) Unemployment and Female Labour Supply, Economic Journal, 97, 44-64.

Blundell, Richard and Ian Walker (1986) A Life-Cycle Consistent Empirical Model of Family Labour Supply Using Cross-Section Data, Review of Economic Studies, 53, 539-558.

Borooah, Vani and Patricia McKee (1996) How Much Did Working Wives Contribute to Changes in Income Inequality Between Couples in the UK?, Fiscal Studies, 17:1, 59-78.

Chiappori, Pierre-André (1992) Collective Labor Supply and Welfare, Journal of Political Economy, 100:3, 437-467.

Child Poverty Action Group (1996) Jobseeker's Allowance Handbook, London: CPAG.

Department of Social Security (1995), Piloting Change in Social Security: Helping People into Work, HMSO, London.

Dex, Shirley, Siv Gustafsson, Nina Smith and Tim Callan (1995), Cross-National Comparison of the Labour Force Participation of Women Married to Unemployed Men, Oxford Economic Papers, 47:4, 611-635.

Dolton, Peter and Donal O'Neill (1995), The Impact of RESTART on Reservation Wage and Long Term Unemployment, Oxford Bulletin of Economics and Statistics, 57, 451-470.

Dilnot, Andrew and Michael Kell (1990) Male Unemployment and Women's Work, in Andrew Dilnot and Ian Walker (eds.) The Economics of Social Security, Oxford University Press.

Dilnot, Andrew and Nick Morris (1983) Private Costs and Benefits of Unemployment: Measuring Replacement Rates: A Critical Review, Oxford Economic Papers, 35, 321-340.

Disney, Richard and Steven Webb (1991) Why are There So Many Long Term Sick in Britain?, Economic Journal, 101, 252-262.

Dynarski, Mark and Steven Sheffrin (1987) Consumption and Unemployment, Quarterly Journal of Economics, 104, 411-428. 
Fischer, Gregory and Daniel Nagin (1981), Random versus Fixed Coefficient Quantal Choice Models, in Charles Manski and Daniel McFadden (eds.) Structural Analysis of Discrete Data, Cambridge, MA: MIT Press, 273-304.

Garcia, Jaime, (1991) A Participation Model with Non-Convex Budget Sets: The case of wives of the unemployed in Great Britain, Applied Economics, 23, 1401-1416.

Giannelli, Gianna and John Micklewright (1995) Why Do Women Married to Unemployed Men have Low Participation Rates?, Oxford Bulletin of Economics and Statistics, 57:4, 471-486.

Gomulka, Joanna and Nicholas Stern, (1990) The Employment of Married Women in the United Kingdom 1970-83, Economica, 57, 171-199.

Gosling, Amanda, Steve Machin and Costas Meghir, (1994) What Has Happened to Men's Wages Since the Mid-1960's?, Fiscal Studies, 15:4, 63-87.

Gregg, Paul and Johnathan Wadsworth (1996) It Takes Two: Employment Polarisation in the OECD, CEPR Discussion Paper, 304.

Gruber, Johnathan and Julie Cullen (1996) Spousal Labor Supply as Insurance: Does Unemployment Insurance Crowd Out the Added Worker Effect?, NBER Working Paper, 5608.

Hausman, Jerry and David Wise (1978), A Conditional Probit Model for Qualitative Choice: Discrete Decisions Recognizing Interdependence and Heterogeneous Preferences, Econometrica, 46, 403-426.

Hausman, Jerry and Paul Ruud (1984) Family Labor Supply with Taxes, American Economic Review, 74:2, 242-248.

Heckman, James (1993), What Has Been Learned About Labor Supply in the Last 20 Years?, American Economic Review, 82:2, 116-121.

Heckman, James and Thomas MaCurdy (1980), A Life Cycle Model of Female Labor Supply, Review of Economic Studies, 47, 47-74.

Heckman, James and Thomas MaCurdy (1982), Corrigendum on A Life Cycle Model of Female Labor Supply, Review of Economic Studies, 49, 659-660.

Hoynes, Hilary (1996a), Welfare Transfers in Two-Parent Families: The Case of AFDC-UP, Econometrica, 64:2, 295-332.

Hoynes, Hilary (1996b) Local Labor Markets and Welfare Spells: Do Demand Conditions Matter?, NBER Working Paper, 5643.

Hoynes, Hilary (1996c) Work, Welfare and Family Structure: What Have We Learned?, NBER Working Paper, 5644.

Jenkins, Steve (1995), Accounting for Inequality Trends: Decomposition analyses for the UK 1971-86, Economica, 62, 29-63.

Johnson, Paul, Graham Stark, and Steven Webb (1990), TAXBEN2: the New IFS Tax-Benefit Model, IFS Working Paper, 90:5.

Juhn, Chinhui and Kevin Murphy (1996) Wage Inequality and Family Labor Supply, NBER Working Paper, 5459.

Katz, Lawrence and Bruce Meyer (1990) The Impact of the Potential Duration of Unemployment Benefits on the Duration of Unemployment, Journal of Public Economics, 41:1, 45-72.

Kell, Michael and Jane Wright (1990) Benefits and the Labour Supply of Women Married to Unemployed Men, Economic Journal, 100, 119-126. 
Layard, Richard, M. Barton and Antonio Zabalza (1980) Married Women's Participation and Hours, Economica, 47, 51-72.

Lundberg, Shelly (1985) The Added Worker Effect, Journal of Labor Economics, 3:1, 11-37.

Machin, Steve and Jane Waldfogel (1994), The Decline of the Male Breadwinner, LSE STICERD Discussion Paper 10.

MaCurdy, Thomas, David Green and Harry Paarsch (1990), Assessing empirical approaches for analysing taxes and labour supply, Journal of Human Resources, 25, 415-490.

Maloney, Tim (1991) Unobserved Variables and the Elusive Added Worker Effect, Economica, 58, $173-187$.

McFadden, Daniel (1984), Econometric Analysis of Qualitative Response Models, in Zvi Griliches and Michael D. Intriligator (eds.), Handbook of Econometrics Vol II, New York: Elsevier, 1396-1457.

Meghir, Costas and Edward Whitehouse, (1996) The Evolution of Wages in the United Kingdom: Evidence from Micro Data, Journal of Labor Economics, 14:1, 1-25.

Micklewright, John (1985) On Earnings Related Unemployment Benefits and their Relation to Earnings, Economic Journal, 95, 133-145.

Moffitt, Robert (1984) The Estimation of a Joint Wage-Hours Labor Supply Model, Journal of Labor Economics, 2:4, 550-566.

Moffitt, Robert (1985) Unemployment Insurance and the Distribution of Unemployment Spells, Journal of Econometrics, 28:1, 85-101.

Moffitt, Robert (1992), The Incentive Effects of the US Welfare System: A Survey, Journal of Economic Literature, 92, 1-61.

Narendranathan, Wiji, Stephen Nickell and J Stern (1985) Unemployment Benefits Revisited, Economic Journal, 95, 307-329.

Narendranathan, Wiji and Mark Stewart (1993) How Does the Benefit Effect Vary as Unemployment Spells Lengthen?, Journal of Applied Econometrics, 8, 361-381.

OECD (1995) Employment Outlook, Paris: OECD.

OECD (1996) Labour Force Statistics, Paris: OECD.

Pudney, Stephen (1991) Modelling Individual Choice: The Econometrics of Corners, Kinks and Holes, London: Basil Blackwell.

Zabalza, Antonio, Chris Pissarides and M. Barton (1980) Social Security and the Choice Between Full-time Work, Part-time Work and Retirement, Journal of Public Economics, 14, 245-276. 


\section{Likelihood Appendix}

Stochastic assumptions for the error terms are captured by the following variance-covariance matrix of a multivariate normal distribution:

$$
V\left(\begin{array}{c}
\varepsilon_{1}-\varepsilon_{2} \\
\varepsilon_{1}-\varepsilon_{3} \\
v_{h} \\
v_{w}
\end{array}\right)=\left(\begin{array}{cccc}
1 & \rho_{\varepsilon_{12} \varepsilon_{13}} \sigma_{\varepsilon_{13}} & \rho_{\varepsilon_{12} v_{h}} & 0 \\
\rho_{\varepsilon_{12} \varepsilon_{13}} \sigma_{\varepsilon_{13}} & \sigma_{\varepsilon_{13}}^{2} & \rho_{\varepsilon_{13} v_{h}} \sigma_{\varepsilon_{13}} & 0 \\
\rho_{\varepsilon_{12} v_{h}} & \rho_{\varepsilon_{13} v_{h}} \sigma_{\varepsilon_{13}} & 1 & 0 \\
0 & 0 & 0 & 1
\end{array}\right)
$$

The variance of the first error difference is normalised to one, so that the variance of $\left(\varepsilon_{1}-\varepsilon_{3}\right)$ may be estimated up to scale. Unemployment duration is discretized and these error variances are normalized to one. ${ }^{39} \mathrm{We}$ assume wife unemployment error terms and labour supply error terms are uncorrelated. This is motivated by a practical concern to keep the dimensionality of the problem down. Following Blundell, Ham and Meghir (1991), in order to capture discouragement we include demand side variables (monthly regional total unemployment rate) in the choice equation. ${ }^{40}$ This leaves education (directly) as the only variable in the ration equation that is not in the choice equation (indirectly it comes into the choice through the predicted wage, tax system and into net incomes). We consider this too weak a motivation to identify the correlation. ${ }^{41}$ However, husband unemployment correlation with female labour supply is clearly identified through the education and age of the husband. Consider a typical likelihood contribution, say, in the case where the husband is medium-term unemployed.

$$
L_{h \in M T}=\left\{\begin{array}{l}
\prod_{w \in N P}\left(\Phi_{3}\left(X \omega_{12}, \frac{X \omega_{13}}{\sigma}, Z^{h} \tau^{h}+\mu_{2}^{h}\right)-\Phi_{3}\left(X \omega_{12}, \frac{X \omega_{13}}{\sigma}, Z^{h} \tau^{h}+\mu_{1}^{h}\right)\right) \\
\prod_{w \in P T}\left(\Phi_{3}\left(-X \omega_{12}, \frac{X\left(\omega_{13}-\omega_{12}\right)}{\sqrt{1+\sigma^{2}-2 \rho_{\varepsilon, \varepsilon} \sigma}} Z^{h} \tau^{h}+\mu_{2}^{h}\right)-\Phi_{3}\left(-X \omega_{12}, \frac{X\left(\omega_{13}-\omega_{12}\right)}{\sqrt{1+\sigma^{2}-2 \rho_{\varepsilon, \varepsilon} \sigma}} Z^{h} \tau^{h}+\mu_{1}^{h}\right)\right) \Phi_{1}\left(Z^{w} \tau^{w}\right) \\
\prod_{w \in F T}\left(\Phi_{3}\left(\frac{X\left(\omega_{12}-\omega_{13}\right)}{\sqrt{1+\sigma^{2}-2 \rho_{\varepsilon, \varepsilon} \sigma}} \frac{-X \omega_{12}}{\sigma}, Z^{h} \tau^{h}+\mu_{2}^{h}\right)-\Phi_{3}\left(\frac{X\left(\omega_{12}-\omega_{13}\right)}{\sqrt{1+\sigma^{2}-2 \rho_{\varepsilon, \varepsilon} \sigma}} \frac{-X \omega_{12}}{\sigma}, Z^{h} \tau^{h}+\mu_{1}^{h}\right)\right) \Phi_{1}\left(Z^{w} \tau^{w}\right) \\
\prod_{w \in S T}\left(\Phi_{3}\left(-X \omega_{12}, \frac{-X \omega_{13}}{\sigma}, Z^{h} \tau^{h}+\mu_{2}^{h}\right)-\Phi_{3}\left(-X \omega_{12}, \frac{-X \omega_{13}}{\sigma}, Z^{h} \tau^{h}+\mu_{1}^{h}\right)\right)\left(\Phi_{1}\left(Z^{w} \tau^{w}+\mu_{1}^{w}\right)-\Phi_{1}\left(Z^{w} \tau^{w}\right)\right) \\
\prod_{w \in M T}\left(\Phi_{3}\left(-X \omega_{12}, \frac{-X \omega_{13}}{\sigma}, Z^{h} \tau^{h}+\mu_{2}^{h}\right)-\Phi_{3}\left(-X \omega_{12}, \frac{-X \omega_{13}}{\sigma}, Z^{h} \tau^{h}+\mu_{1}^{h}\right)\right)\left(\Phi_{1}\left(Z^{w} \tau^{w}+\mu_{2}^{w}\right)-\Phi_{1}\left(Z^{w} \tau^{w}+\mu_{1}^{w}\right)\right) \\
\prod_{w \in L T}\left(\Phi_{3}\left(-X \omega_{12}, \frac{-X \omega_{13}}{\sigma}, Z^{h} \tau^{h}+\mu_{2}^{h}\right)-\Phi_{3}\left(-X \omega_{12}, \frac{-X \omega_{13}}{\sigma}, Z^{h} \tau^{h}+\mu_{1}^{h}\right)\right)\left(1-\Phi_{1}\left(Z^{w} \tau^{w}+\mu_{2}^{w}\right)\right)
\end{array}\right.
$$

where $\Phi_{1}$ and $\Phi_{3}$ are respectively univariate and trivariate normal cumulative distribution functions.

39 Estimating weeks away from work directly would allow us to incorporate this additional information and identify these variances. Independent Tobits for husband and wife unemployment duration work well. However, estimating these jointly with the full model, we encountered convergence difficulties, and this set-up was not pursued. Suggestions for an appropriate transformation of these variance terms are welcomed.

40 Blundell, Ham and Meghir (1991) estimate a Bivariate Probit for participation and conditional employment and use this as a selection into an hours equation. They put demand side variables into the participation equation to identify discouraged workers.

41 Blundell, Ham and Meghir (1987) estimate a double hurdle model (using the same searching question) and find a significant correlation between the error terms. However they go on to show that this makes little difference to the parameter estimates. 
Data Appendix

Table A1 Descriptive Statistics by Female Labour Supply and Unemployment Means (standard deviations)

\begin{tabular}{|c|c|c|c|c|c|c|c|}
\hline \multirow[t]{2}{*}{ Variable } & \multirow[t]{2}{*}{ All } & \multicolumn{3}{|c|}{ Choice } & \multicolumn{3}{|c|}{ Ration } \\
\hline & & FT & PT & NP & ST & $\mathrm{MT}$ & $\mathrm{LT}$ \\
\hline Wage $_{\mathrm{PT}}{ }^{\mathrm{w}}$ & $3.942(1.224)$ & $4.553(1.428)$ & $3.632(1.027)$ & $3.752(1.040)$ & $3.919(1.150)$ & $3.962(1.026)$ & $3.956(1.169)$ \\
\hline Wage $_{\mathrm{FT}}$ & $4.175(0.969)$ & $4.468(1.071)$ & $4.191(0.918)$ & $3.923(0.861)$ & $4.127(0.908)$ & $4.010(0.854)$ & $4.108(0.901)$ \\
\hline Wage $_{\text {OT }}$ & $6.412(2.198)$ & $6.335(2.074)$ & $6.296(2.046)$ & $6.604(2.414)$ & $6.185(2.177)$ & $6.029(2.216)$ & $6.737(2.482)$ \\
\hline Wage $_{R T}$ & $6.224(1.116)$ & $6.252(1.113)$ & $6.238(1.071)$ & $6.253(1.162)$ & $6.106(1.105)$ & $6.004(1.117)$ & $6.315(1.152)$ \\
\hline Income $_{\mathrm{NP}}$ & $0.159(0.085)$ & $0.158(0.083)$ & $0.163(0.084)$ & $0.155(0.086)$ & $0.150(0.076)$ & $0.149(0.079)$ & $0.152(0.081)$ \\
\hline Income $_{\mathrm{PT}}$ & $0.213(0.090)$ & $0.222(0.090)$ & $0.215(0.088)$ & $0.205(0.092)$ & $0.205(0.082)$ & $0.203(0.084)$ & $0.205(0.087)$ \\
\hline Income $_{\mathrm{FT}}$ & $0.251(0.093)$ & $0.259(0.092)$ & $0.257(0.091)$ & $0.238(0.095)$ & $0.242(0.085)$ & $0.238(0.087)$ & $0.238(0.090)$ \\
\hline $\operatorname{Age}_{w}$ & $0.216(0.106)$ & $0.206(0.108)$ & $0.234(0.094)$ & $0.210(0.113)$ & $0.185(0.108)$ & $0.161(0.110)$ & $0.173(0.105)$ \\
\hline $\mathrm{Age}_{\mathrm{h}}$ & $0.243(0.110)$ & $0.233(0.113)$ & $0.259(0.098)$ & $0.238(0.117)$ & $0.208(0.112)$ & $0.187(0.114)$ & $0.196(0.108)$ \\
\hline Education $_{\mathrm{w}}$ & $0.206(0.198)$ & $0.241(0.218)$ & $0.194(0.193)$ & $0.187(0.182)$ & $0.215(0.191)$ & $0.203(0.179)$ & $0.229(0.190)$ \\
\hline Education $_{h}$ & $0.207(0.225)$ & $0.229(0.240)$ & $0.190(0.214)$ & $0.205(0.224)$ & $0.227(0.225)$ & $0.216(0.204)$ & $0.222(0.213)$ \\
\hline Unemp' & $0.892(0.383)$ & $0.861(0.378)$ & $0.876(0.377)$ & $0.923(0.390)$ & $0.958(0.375)$ & $1.033(0.372)$ & $1.007(0.366)$ \\
\hline No Children & 0.402 & 0.659 & 0.317 & 0.278 & 0.426 & 0.325 & 0.290 \\
\hline Y Kid 0-4 & 0.244 & 0.070 & 0.186 & 0.436 & 0.237 & 0.442 & 0.481 \\
\hline Y Kid 5-10 & 0.173 & 0.094 & 0.249 & 0.164 & 0.194 & 0.149 & 0.122 \\
\hline Y Kid 11-18 & 0.181 & 0.177 & 0.248 & 0.122 & 0.144 & 0.084 & 0.107 \\
\hline Renter & 0.608 & 0.595 & 0.601 & 0.621 & 0.615 & 0.669 & 0.700 \\
\hline London & 0.092 & 0.109 & 0.082 & 0.089 & 0.077 & 0.057 & 0.076 \\
\hline North & 0.064 & 0.058 & 0.064 & 0.068 & 0.063 & 0.070 & 0.072 \\
\hline Yorkshire & 0.093 & 0.079 & 0.099 & 0.098 & 0.099 & 0.108 & 0.102 \\
\hline N. West & 0.112 & 0.116 & 0.113 & 0.106 & 0.120 & 0.136 & 0.138 \\
\hline E. Mids & 0.076 & 0.079 & 0.078 & 0.073 & 0.077 & 0.057 & 0.066 \\
\hline W. Mids & 0.099 & 0.099 & 0.097 & 0.101 & 0.098 & 0.095 & 0.117 \\
\hline E. Anglia & 0.037 & 0.035 & 0.040 & 0.035 & 0.035 & 0.016 & 0.038 \\
\hline S. West & 0.073 & 0.070 & 0.077 & 0.073 & 0.088 & 0.079 & 0.061 \\
\hline Wls,Scot,NI & 0.166 & 0.159 & 0.149 & 0.184 & 0.194 & 0.233 & 0.199 \\
\hline S. East & 0.188 & 0.197 & 0.201 & 0.173 & 0.148 & 0.149 & 0.130 \\
\hline 1978 & 0.073 & 0.076 & 0.070 & 0.076 & 0.047 & 0.038 & 0.025 \\
\hline $1979-80$ & 0.140 & 0.140 & 0.147 & 0.138 & 0.121 & 0.111 & 0.063 \\
\hline $1981-82$ & 0.154 & 0.140 & 0.152 & 0.165 & 0.224 & 0.179 & 0.153 \\
\hline $1983-84$ & 0.141 & 0.127 & 0.141 & 0.148 & 0.145 & 0.190 & 0.186 \\
\hline $1985-86$ & 0.136 & 0.130 & 0.129 & 0.146 & 0.137 & 0.179 & 0.166 \\
\hline $1987-88$ & 0.129 & 0.136 & 0.127 & 0.124 & 0.115 & 0.149 & 0.188 \\
\hline $1989-90$ & 0.118 & 0.129 & 0.124 & 0.106 & 0.099 & 0.068 & 0.109 \\
\hline $1991-92$ & 0.109 & 0.121 & 0.111 & 0.097 & 0.110 & 0.087 & 0.110 \\
\hline Observations & is 43531 & 12241 & 15084 & 14596 & 634 & 369 & 607 \\
\hline
\end{tabular}


Table A2 Descriptive Statistics by Husband Unemployment Duration Means (standard deviations)

\begin{tabular}{|c|c|c|c|c|c|}
\hline \multirow[t]{2}{*}{ Variable } & \multirow[b]{2}{*}{ All } & \multicolumn{4}{|c|}{ Unemployment Duration } \\
\hline & & None & ST & MT & LT \\
\hline Wage $_{\mathrm{PT}}{ }^{\mathrm{w}}$ & $3.942(1.224)$ & $3.983(1.254)$ & $3.815(1.123)$ & $3.592(0.841)$ & $3.533(0.751)$ \\
\hline Wage $_{\mathrm{FT}}$ & $4.175(0.969)$ & $4.218(0.981)$ & $4.028(0.906)$ & $3.816(0.785)$ & $3.777(0.737)$ \\
\hline Wage $_{\mathrm{OT}}$ & $6.412(2.198)$ & $6.358(2.140)$ & $5.904(1.958)$ & $5.917(2.157)$ & $9.408(1.952)$ \\
\hline Wage $_{\mathrm{RT}}$ & $6.224(1.116)$ & $6.249(1.114)$ & $5.978(1.055)$ & $5.894(1.050)$ & $7.067(0.938)$ \\
\hline Income $_{\mathrm{NP}}$ & $0.159(0.085)$ & $0.163(0.086)$ & $0.146(0.077)$ & $0.135(0.070)$ & $0.094(0.037)$ \\
\hline Income $_{\mathrm{PT}}$ & $0.213(0.090)$ & $0.219(0.090)$ & $0.200(0.081)$ & $0.184(0.075)$ & $0.125(0.047)$ \\
\hline Income $_{\mathrm{FT}}$ & $0.251(0.093)$ & $0.257(0.093)$ & $0.237(0.083)$ & $0.220(0.077)$ & $0.150(0.046)$ \\
\hline $\operatorname{Age}_{w}$ & $0.216(0.106)$ & $0.217(0.105)$ & $0.210(0.109)$ & $0.213(0.119)$ & $0.203(0.113)$ \\
\hline $\mathrm{Age}_{\mathrm{h}}$ & $0.243(0.110)$ & $0.244(0.109)$ & $0.234(0.114)$ & $0.241(0.125)$ & $0.237(0.120)$ \\
\hline Education $_{w}$ & $0.206(0.198)$ & $0.212(0.202)$ & $0.189(0.188)$ & $0.149(0.142)$ & $0.141(0.121)$ \\
\hline Education $_{\mathrm{h}}$ & $0.207(0.225)$ & $0.214(0.230)$ & $0.185(0.209)$ & $0.148(0.170)$ & $0.136(0.141)$ \\
\hline Unemp' & $0.892(0.383)$ & $0.876(0.379)$ & $0.919(0.384)$ & $1.036(0.385)$ & $1.095(0.386)$ \\
\hline No Children & 0.402 & 0.409 & 0.387 & 0.383 & 0.266 \\
\hline Y Kid 0-4 & 0.244 & 0.234 & 0.269 & 0.306 & 0.380 \\
\hline Y Kid 5-10 & 0.173 & 0.172 & 0.178 & 0.168 & 0.199 \\
\hline Y Kid 11-18 & 0.181 & 0.185 & 0.167 & 0.143 & 0.155 \\
\hline Renter & 0.608 & 0.593 & 0.618 & 0.726 & 0.870 \\
\hline London & 0.092 & 0.095 & 0.076 & 0.066 & 0.084 \\
\hline North & 0.064 & 0.060 & 0.086 & 0.083 & 0.089 \\
\hline Yorkshire & 0.093 & 0.091 & 0.100 & 0.119 & 0.109 \\
\hline N. West & 0.112 & 0.109 & 0.126 & 0.118 & 0.142 \\
\hline E. Midlands & 0.076 & 0.077 & 0.076 & 0.091 & 0.052 \\
\hline W. Midlands & 0.099 & 0.098 & 0.095 & 0.109 & 0.129 \\
\hline E. Anglia & 0.037 & 0.038 & 0.027 & 0.029 & 0.022 \\
\hline S. West & 0.073 & 0.076 & 0.068 & 0.055 & 0.047 \\
\hline Wales,Scot,NI & 0.166 & 0.160 & 0.181 & 0.200 & 0.233 \\
\hline S. East & 0.188 & 0.197 & 0.165 & 0.130 & 0.094 \\
\hline 1978 & 0.073 & 0.073 & 0.091 & 0.047 & 0.013 \\
\hline $1979-80$ & 0.140 & 0.143 & 0.162 & 0.091 & 0.038 \\
\hline $1981-82$ & 0.154 & 0.150 & 0.186 & 0.222 & 0.131 \\
\hline $1983-84$ & 0.141 & 0.135 & 0.146 & 0.194 & 0.216 \\
\hline $1985-86$ & 0.136 & 0.135 & 0.126 & 0.149 & 0.180 \\
\hline $1987-88$ & 0.129 & 0.128 & 0.105 & 0.145 & 0.209 \\
\hline $1989-90$ & 0.118 & 0.123 & 0.096 & 0.066 & 0.090 \\
\hline $1991-92$ & 0.109 & 0.112 & 0.087 & 0.086 & 0.124 \\
\hline Observations & 43531 & 36767 & 4285 & 935 & 1544 \\
\hline
\end{tabular}




\section{Figure A1}
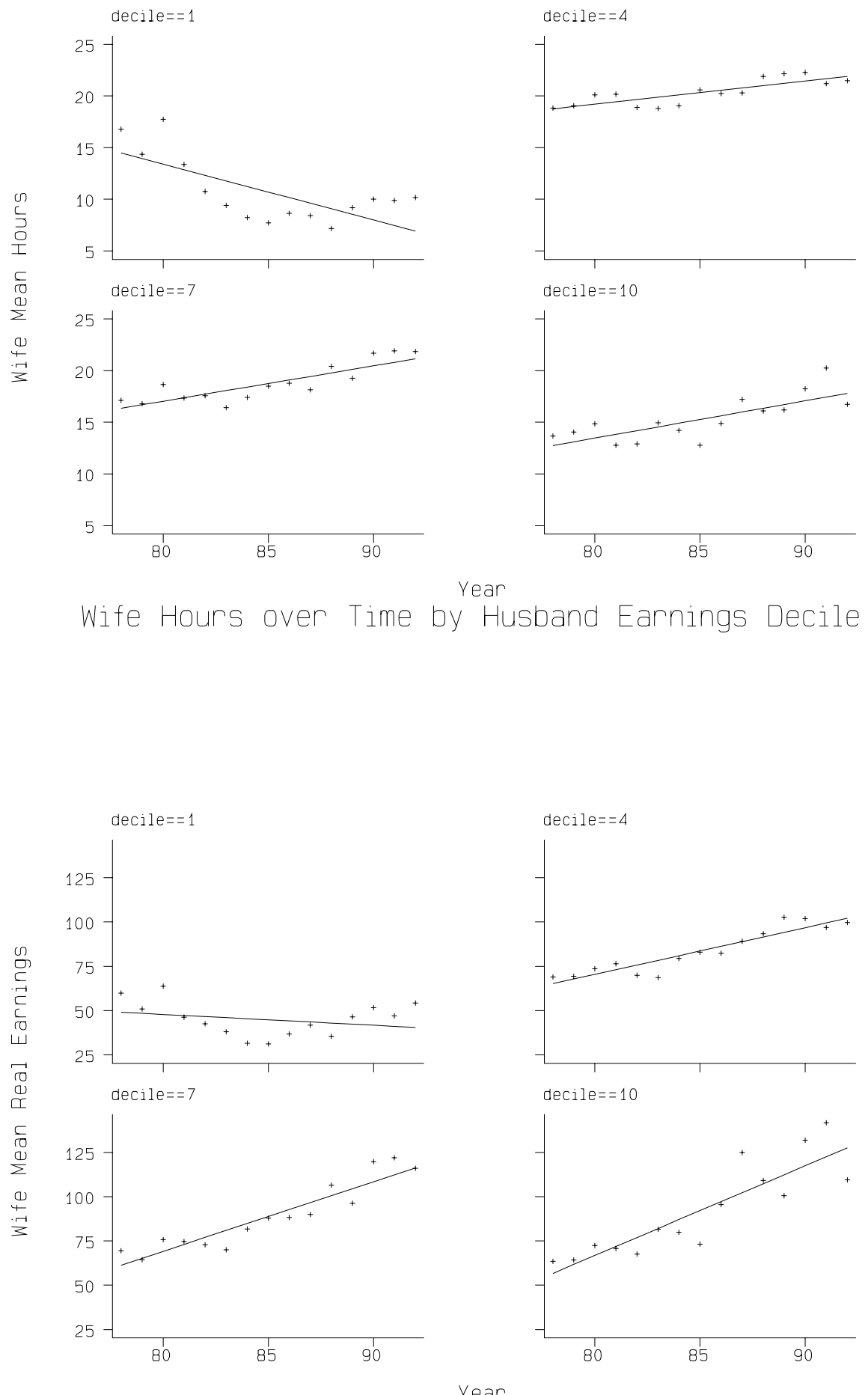

Wife Earnings over Time

Year

by Husband Earnings Decile 
Figure A2
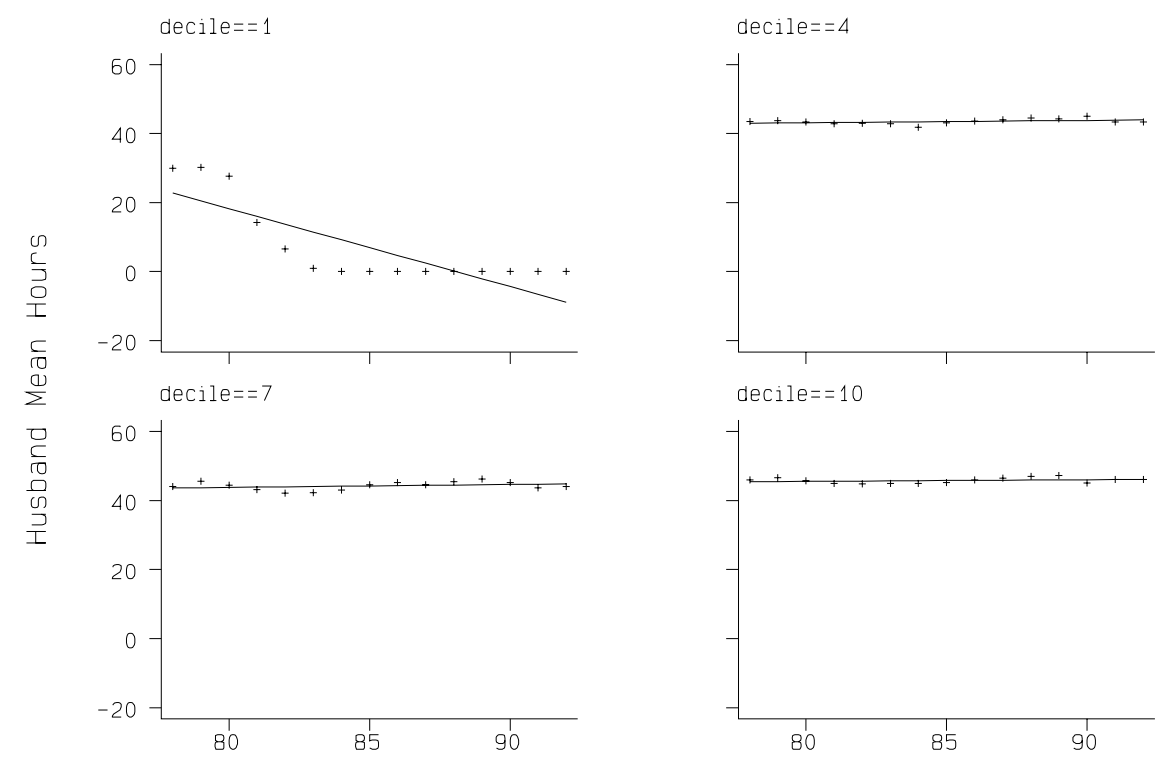

Husband Hours over Time

Year

by Husband Earnings Decile
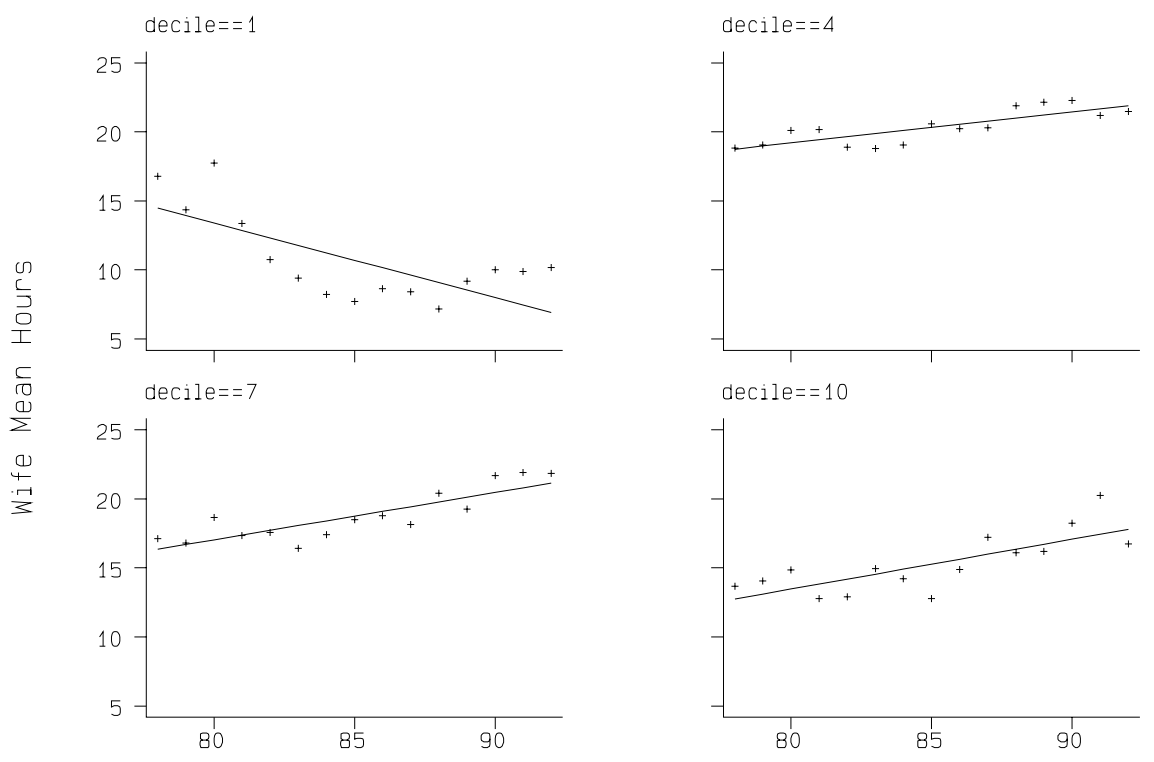

Year

Wife Hours over Time by Husband Earnings Decile 
Table $7 \quad$ Selected Simulations for a Representative Individual $\%$ Expected by State

\begin{tabular}{|c|c|c|c|c|c|c|c|c|}
\hline \multirow[t]{2}{*}{ Variable } & \multicolumn{4}{|c|}{$\mathrm{R}^{\mathrm{h}}$ Short-term } & \multicolumn{4}{|c|}{$\mathrm{R}^{\mathrm{h}}$ Long-term } \\
\hline & FT & PT & $\mathrm{NP}$ & UE & FT & PT & NP & UE \\
\hline Reference & 27.34 & 43.30 & 25.65 & 3.71 & 17.58 & 24.52 & 55.74 & 2.15 \\
\hline Income $_{\mathrm{NP}}+£ 10$ & -0.75 & -1.88 & 2.77 & -0.14 & -0.94 & -2.07 & 3.17 & -0.16 \\
\hline Income $_{\mathrm{PT}}+£ 10$ & -1.02 & 2.47 & -1.53 & 0.08 & -0.51 & 2.18 & -1.77 & 0.09 \\
\hline Income $_{\mathrm{FT}}+£ 10$ & 1.64 & -0.95 & -0.73 & 0.04 & 1.31 & -0.40 & -0.95 & 0.05 \\
\hline Owner & 4.29 & -1.89 & -1.21 & -1.20 & 3.30 & -0.90 & -1.73 & -0.67 \\
\hline $\mathrm{Age}_{\mathrm{w}}+10$ & -11.34 & 10.68 & 2.02 & -1.36 & -8.20 & 6.31 & 2.71 & -0.82 \\
\hline $\mathrm{Age}_{\mathrm{h}}+10$ & 0.66 & -0.62 & -0.03 & 0.00 & 0.49 & -0.39 & -0.10 & 0.00 \\
\hline Education $_{w}+2$ & 0.06 & 0.09 & 0.05 & -0.20 & 0.02 & 0.03 & 0.07 & -0.12 \\
\hline Education $_{h}+2$ & 0.98 & -0.93 & -0.05 & 0.01 & 0.73 & -0.58 & -0.16 & 0.00 \\
\hline Unemp' + $1 \%$ & -0.31 & -0.52 & 0.62 & 0.21 & -0.31 & -0.53 & 0.74 & 0.10 \\
\hline Child 0-4 & -14.80 & -13.38 & 26.80 & 1.38 & -11.72 & -12.81 & 24.65 & -0.12 \\
\hline Child 11-18 & 27.12 & -12.50 & -14.07 & -0.54 & 25.39 & -3.73 & -21.82 & 0.16 \\
\hline No Children & 48.81 & -29.25 & -19.10 & -0.46 & 48.05 & -14.74 & -33.80 & 0.50 \\
\hline
\end{tabular}

Table 8

Transfer Programme Participation by Husband Unemployment Duration $\%$ Receiving

Transfer Programme

Income Support

Unemployment Benefit

\begin{tabular}{ccc} 
ST & MT & LT \\
\hline 6.7 & 27.9 & 74.7 \\
12.6 & 42.8 & 8.5 \\
17.5 & 1.5 & 0.5 \\
9.9 & 0.7 & 0.2 \\
0.8 & 8.2 & 7.1 \\
0.2 & 0.5 & 0.6 \\
0.0 & 0.1 & 0.1 \\
\hline
\end{tabular}

Sickness Allowance

Statutory Sick Pay

Invalidity Allowance

Disability Living Allowance

Attendance Allowance 
Working

Paper

95-01 Christian Belzil: Contiguous Duration Dependence and Nonstationarity in Job Search

95-02 Christian Belzil: Unemployment Insurance and Unemployment Over Time: An Analysis with Event History Data.

95-03 Christian Belzil: Unemployment Duration Stigma and Reemployment Earnings.

95-04 Christian Belzil: Relative Efficiencies and Comparative Advantages in Job Search.

95-05 Niels Henning Bjørn: Causes and Consequences of Persistent Unemployment.

95-06 Nicholas M. Kiefer and Mark F.J. Steel: Bayesian Analysis of the Prototypal Search Model.

95-07 Nicholas M. Kiefer, Ranjini Natarajan and Charles E. McCulloch: Maximum Likelihood for the Multinomial Probit Model.

95-08 Christian Belzil and Philip Hergel: Fertility and the Human Capital Loss of Non-Participation

95-09 Christian Belzil, William A. Sims and Philip Hergel: Endogeneity, Self-Selectivity and the Sensitivity of Female Earnings to Non-Participation.

95-10 Paul Bingley, Niels Henning Bjørn and Niels Westergård-Nielsen: Wage Mobility in Denmark 1980-1990.

95-11 Audra J. Bowlus, Nicholas M. Kiefer and George R Neumann: Estimation of Equilibrium Wage Distributions with Heterogeneity.

95-12 Anders Björklund and Tor Eriksson: Unemployment and Mental Health: Evidence from Research in the Nordic Countries 
Working

Paper

95-13 Melvyn G. Coles and John G. Treble: Here Today, Gone Tomorrow: Calculating the Price of Worker Reliability.

95-14 Christian Belzil: Employment Reallocation, the Return to Human Capital and the Allocation of Workers Between Expanding and Declining Firms.

95-15 John T. Addison and Jean-Luc Grosso: Job Security Provisions and Employment: Revised Estimates.

95-16 John T. Addison and McKinley L. Blackburn: A Puzzling Aspect of the Effect of Advance Notice on Unemployment.

95-17 Peder J. Pedersen and Nina Smith: The Welfare State and the Labour Market.

95-18 Mette Lausten: Inter-Industry Wage Differentials in Denmark ?

96-01 Mark Yuying An: Log-concave Probability Distributions: Theory and Statistical Testing.

96-02 Audra Bowlus, Nicholas M. Kiefer and George R. Neumann: Fitting Equilibrium Search Models to Labour Market Data.

96-03 Karsten Albæk, Mahmood Arai, Rita Asplund, Erling Barth and Erik Strøyer Madsen: Employer Size-Wage Effects in the Nordic Countries.

96-04 Bent J. Christensen and Nicholas M. Kiefer: Inference in Non-Linear Panels with Partially Missing Observations: The Case of the Equilibrium Search Model.

96-05 Michèle Naur and Nina Smith: Cohort Effects on the Gender Wage Gap in Denmark.

96-06 Elizabeth J. Cunningham: The Relationship between Recruiting and Screening within the Employer Search Framework

96-07 Tim Barmby and Nina Smith: Household Labour Supply in Britain and Denmark: Some Interpretations Using a Model of Pareto Optimal Behaviour.

96-08 Michael Rosholm: Unemployment Duration over the Business Cycle.

96-09 Mark Yuying An and Ming Liu: Structural Analysis of Labor Market Transitions Using Indirect Inference 
Working

Paper

96-10 Paul Bingley and Niels Westergård-Nielsen: Worker and Plant Wages: Estimates from a Multi-Level Model

96-11 Paul Bingley and Gauthier Lanot: Danish Private Sector Wage Policies and Male Retirement Decisions

96-12 George R. Neumann and Gauthier Lanot: Measuring Productivity Differences in Equilibrium Search Models.

96-13 Tor Eriksson: Executive Compensation and Tournament Theory: Empirical Tests on Danish Data.

96-14 Peter Jensen and Helena Skyt Nielsen: Child Labour or School Attendance ? Evidence from Zambia.

96-15 Ebbe Krogh Graversen: Male and Female Labour Supply in Denmark.

96-16 Tor Eriksson and Markus Jäntti: The Distribution of Earnings in Finland 19711990.

96-17 Ebbe Krogh Graversen: Measuring Labour Supply Responses to Tax Changes by Use of Exogenous Tax Reforms.

97-01 Report $1993-1996$.

97-02 Paul Bingley and Ian Walker: Labour Supply with In-Work and In-Kind Trans fers.

97-03 Paul Bingley and Ian Walker: Household Unemployment and the Labour Supply of Married Women.

97-04 Christian Belzil: Job Creation and Destruction, Worker Reallocation and Wages.

97-05 Christian Belzil: The Dynamics of Female Time Allocation upon a First Birth

97-06 Christian Belzil and Jörgen Hansen: Estimating the Returns to Education from a Non-Stationary Dynamic Programming Model

97-07 Niels Westergård-Nielsen and Anders Rue Rasmussen: Apprenticeship Training in Denmark - the impacts of subsidies. 
97-08 H. Bunzel, B.J. Christensen, P. Jensen, N.M. Kiefer, L. Korsholm, L. Muus, G.R. Neumann, M. Rosholm: Specification and Estimation of Equilibrium Search Models.

97-09 Ebbe Krogh Graversen: Work disincentive effects of taxes among Danish married men and women

97-10 Jukka Vittaniemi: Top Executive Compensation and Company Performance in Finland.

97-11 Peder J. Pedersen and Nina Smith: Trends in the Danish Income Distribution, 1976-90.

97-12 Ronald L. Oaxaca and Michael R. Ransom: Identification in Detailed Wage Decompositions

97-13 Bent J. Christensen and Nicholas M. Kiefer: Panel Data, Local Cuts and Orthogeodesic Models

97-14 Michael Rosholm: The risk of marginalization in the labour market: Application of a three state dependent competing risks duration model.

97-15 Helena Skyt Nielsen and Michael Rosholm: The Incidence of Unemployment: Identifying Quits and Layoffs

97-16 Tor Eriksson: Long-Term Earnings Mobility of Low-Paid Workers

97-17 Lars Korsholm: The Semiparametric Normal Variance-Mean Mixture Model 

ISSN 0908-8962

\section{CENTRE FOR LABOUR MARKET AND SOCIAL RESEARCH} Science Park Aarhus, Gustav Wieds Vej 10C, 8000 Aarhus C, Denmark Phone: +4589422350Ｆax: +4589422365Ｅmail: cls@cls.dkＷWW: http://www.cls.dk 